


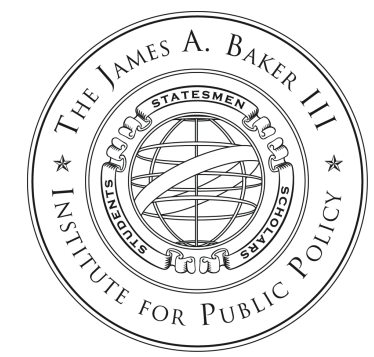

James A. Baker III Institute for Public Policy

RICE UNIVERSITY

\title{
THE FUTURE OF LONG-TERM LNG CONTRACTS
}

\author{
BY \\ Peter Hartley, Ph.D. \\ BAKER INSTITUTE FACULTY SCHOLAR \\ AND \\ George And Cynthia Mitchell Chair \\ in Sustainable Development and Environmental ECONOMics \\ RICE UNIVERSITY
}

OCtOber 31, 2013 
THESE PAPERS WERE WRITTEN BY A RESEARCHER (OR RESEARCHERS) WHO PARTICIPATED IN A BAKER INSTITUTE RESEARCH PROJECT. WhEREVER FEASIBLE, THESE PAPERS ARE REVIEWED by OUTSIDE EXPERTS BEFORE THEY ARE RELEASED. HOWEVER, THE RESEARCH AND VIEWS EXPRESSED IN THESE PAPERS ARE THOSE OF THE INDIVIDUAL RESEARCHER(S), AND DO NOT NECESSARILY REPRESENT THE VIEWS OF THE JAMES A. BAKER III INSTITUTE FOR PUBLIC POLICY.

(C) 2013 By the James A. BAker III Institute for P UbliC POlicy Of RiCe University

THIS MATERIAL MAY BE QUOTED OR REPRODUCED WITHOUT PRIOR PERMISSION, PROVIDED APPROPRIATE CREDIT IS GIVEN TO THE AUTHOR AND THE JAMES A. BAKER III INSTITUTE FOR PUBLIC POLICY. 


\section{ACKNOWLEDGMENTS}

The Center for Energy Studies of Rice University's Baker Institute would like to thank ConocoPhillips and the sponsors of the Baker Institute Center for Energy Studies for their generous support of this program. The Center for Energy Studies further acknowledges the contributions by study researchers and writers.

\section{ENERGY FORUM MEMBERS}

ADVISORY BOARD

Accenture

The Honorable \& Mrs. Hushang Ansary

Baker Botts L.L.P.

Baker Hughes Incorporated

BP

California Energy Commission

Cheniere Energy, Inc.

Chevron Corporation

ConocoPhillips

Deloitte

EDP Renewables North America, LLC

Energy Future Holdings Corporation

ExxonMobil Corporation

The Institute of Energy Economics, Japan (IEEJ)

Marathon Oil Corporation

Saudi Aramco

Schlumberger

Shell Oil Company

Shell Exploration \& Production Co.

Trinity Industries, Inc.

Wallace S. Wilson
ASSOCIATE MEMBERS

Direct Energy

Hess Corporation

Tudor, Pickering, Holt \& Co. LLC

MEMBERS

Afren Resources USA

Air Products and Chemicals, Inc.

American Air Liquide Holdings, Inc.

Apache Corporation

Aramco Services Company

IPR - GDF SUEZ North America

Pioneer Natural Resources USA Inc.

Rockwater Energy Solutions, Inc.

TOTAL E\&P New Ventures, Inc.

TOTAL E\&P USA, Inc.

VAALCO Energy

SUPPORTING MEMBERS

Deloitte MarketPoint LLC

Energy Intelligence 


\section{ACKNOWLEDGMENTS}

The Geopolitics of Energy Project at Harvard University's Kennedy School is grateful for the support it receives from BP, as well as the Belfer Center for Science and International Affairs. It also appreciates the work and contributions provided by the scholars who have participated in this program. 


\section{ABOUT THE STUDY}

Some of the most dramatic energy developments of recent years have been in the realm of natural gas. Huge quantities of unconventional U.S. shale gas are now commercially viable, changing the strategic picture for the United States by making it self-sufficient in natural gas for the foreseeable future. This development alone has reverberated throughout the globe, causing shifts in patterns of trade and leading other countries in Europe and Asia to explore their own shale gas potential. Such developments are putting pressure on longstanding arrangements, such as oil-linked gas contracts and the separate nature of North American, European, and Asian gas markets, and may lead to strategic shifts, such as the weakening of Russia's dominance in the European gas market.

Against this backdrop, the Center for Energy Studies of Rice University's Baker Institute and the Belfer Center for Science and International Affairs of Harvard University's Kennedy School launched a two-year study on the geopolitical implications of natural gas. The project brought together experts from academia and industry to explore the potential for new quantities of conventional and unconventional natural gas reaching global markets in the years ahead. The effort drew on more than 15 country experts of producer and consumer countries who assessed the prospects for gas consumption and production in the country in question, based on anticipated political, economic, and policy trends. Building on these case studies, the project formulated different scenarios and used the Rice World Gas Trade Model to assess the cumulative impact of country-specific changes on the global gas market and geopolitics more broadly.

\section{STUDY AUTHORS}

Rawi Abdelal
Luay Al Khatteeb
Govinda Avasarala
Beibei Bao
Soner Cagaptay
Charles Ebinger
Jareer Elass
Andreas Goldthau
Peter Hartley

Rawi Abdelal

Govinda Avasarala

Beibei Bao

Soner Cagaptay

Charles Ebinger

Andreas Goldthau

Peter Hartley

Simon Henderson
Trevor Houser
Amy Myers Jaffe
Robert Johnston
Ken Koyama
Azzedine Layachi
Michael Levi
Steven Lewis
Suzanne Maloney

Simon Henderson

David Mares

Kenneth B. Medlock

Keily Miller

Tatiana Mitrova

Isidro Morales

Martha Brill Olcott

Meghan O'Sullivan

Ronald Ripple 


\section{Executive Summary}

Long-term contracts have long dominated the international market for LNG. Since 2000, however, the proportion of LNG-traded spot or under short-term contracts has grown substantially. Long-term contracts between exporters and importers of LNG have the advantage of reducing cash flow variability and thereby increasing the debt capacity of large, long-lived capital investments for both the exporter and the importer (debt has tax advantages vs. equity financing). However, long-term contracts also limit the ability of the contracting parties to take advantage of profitable short-term trading opportunities.

The paper presents a model that illustrates these trade-offs. Additional debt under the contract, and the benefits of a long-term contract relative to spot market trade, are both shown to increase substantially with increasing spot price variability. Take-or-pay provisions and supplemental spot market trades limit the inefficiencies arising from contract limitations on trading outside of the long-term contract. A smaller gap between average spot prices available to the exporter and the importer reduces the advantages of a long-term contract, while also encouraging substantially more spot market trading by parties to the contract. Changes in the variability of spot prices have complicated effects on contract price and volume, ex-post inefficiencies of contractual limits on trading, and, to a lesser extent, the volume of spot market transactions undertaken by contracted parties.

A key implication of the analysis is that increased LNG market liquidity as a result of increased participation by new suppliers and customers is likely to encourage much greater volume and destination flexibility in long-term LNG contracts and even greater reliance on short-term and spot market trades. These changes would, in turn, reinforce the initial increase in market liquidity.

Based on our analysis, we foresee a continuing evolution of world LNG markets toward a larger proportion of volumes being traded on short-term contracts or sold as spot cargoes, and an increased use of swaps, re-exports and other short-term arrangements to take advantage of 
temporary arbitrage opportunities. Conversely, volumes moved under long-term contracts can be expected to decline in the years ahead

\section{Introduction ${ }^{1}$}

Traditionally, LNG was almost exclusively traded under inflexible long-term contracts. Since 2000, however, the proportion of LNG traded spot or on contracts of less than four years duration has risen substantially. In addition, as emphasized by Weems (2006), long-term LNG contracts have become more flexible. For example, recent contracts allow quantity adjustments to cope with a multitude of circumstances, much greater destination flexibility, a much wider range of pricing options (including linking LNG prices to spot market natural gas prices) and price review provisions. Such contract provisions allow parties not only to cope with temporary operational disruptions but also to exploit profitable short-term trading opportunities.

This paper develops a model of the costs and benefits of optimal long-term contracts, where "optimal" is defined as a contract giving the largest combined expected net present value to the trading partners. We then use the model to analyze how increases in spot market liquidity affect such optimal contracts. Higher market liquidity is associated with increased ability to trade without adversely affecting prices, reduced price variability, and smaller gaps between buying and selling prices. We show that increased spot market liquidity reduces the net benefits of a long-term contract for parties establishing new LNG projects. Increased spot market liquidity also raises the benefits of participating in spot markets for partners in existing long-term contracts. If long-term contract terms are adjusted to allow firms to exploit these trading opportunities, spot market liquidity will increase further.

We conclude that the proportion of LNG traded on long-term contracts is likely to further diminish over the coming decade. Even if most LNG trade continues to be covered by long-term contracts, such contracts are likely to continue evolving toward offering much greater volume and destination flexibility.

\footnotetext{
${ }^{1}$ Research support from the James A. Baker III Institute for Public Policy and assistance from Mark Agerton and Michael Maher at Rice University are gratefully acknowledged.
} 


\section{Some Recent Developments in LNG Markets}

Figure 1, based on data from the International Group of Liquefied Natural Gas Importers (GIIGNL), shows that spot and short-term (less than four-year duration) contract trades generally increased from 2000 to more than 25\% of total trade in 2011. Furthermore, since contracted volume plus spot and short-term trade exceeded actual trade every year since 2001 in both basins, parties to long-term contracts evidently engaged in spot and short-term trade. The model we develop later will allow for such short-term trades.

Writing in the IGU 2006-2009 Triennium Work Report (International Gas Union (2009), hereafter IGU (2009)), Lange notes that the first swaps were arranged to save transportation costs or satisfy ephemeral peak demands. Surplus volumes from temporary demand reductions were also sold into US terminals, which acted as a sink for the global LNG market. In the five years before he wrote, however, traders seeking to profit from arbitrage opportunities increasingly dominated the market.

Park, also writing in IGU (2009), remarked that the then recently signed contract between Malaysian LNG (Tiga) and three Japanese customers allowed for 40\% volume flexibility instead of the $5-10 \%$ in a conventional contract. Nakamura (also in IGU (2009)) noted that some then recent LNG export projects had made final investment decisions without $100 \%$ off-take commitments by buyers. This left uncommitted quantities available for spot market trades. Nakamura also discussed growth in "Branded LNG," where non-consuming buyers purchase LNG from multiple projects and sell to buyers under their own names. Similarly, Thompson (2009) notes that BG has signed contracts with several suppliers that allow it divert LNG to higher-value markets as the opportunity arises. To support this activity, BG has abundant shipping capacity and considerable storage capacity at Lake Charles, Louisiana and the Dragon terminal in Wales. In fact, many major liquefaction and regasification terminals have substantial on-site LNG storage. National Grid sells available capacity in a dedicated LNG storage facility at Avonmouth in the UK. Singapore is building a regasification terminal with throughput capacity surplus to domestic needs aimed at pursuing arbitrage opportunities in the LNG market. 
Figure 1. Total, contracted and spot and short-term LNG trade by destination basin

Atlantic Basin

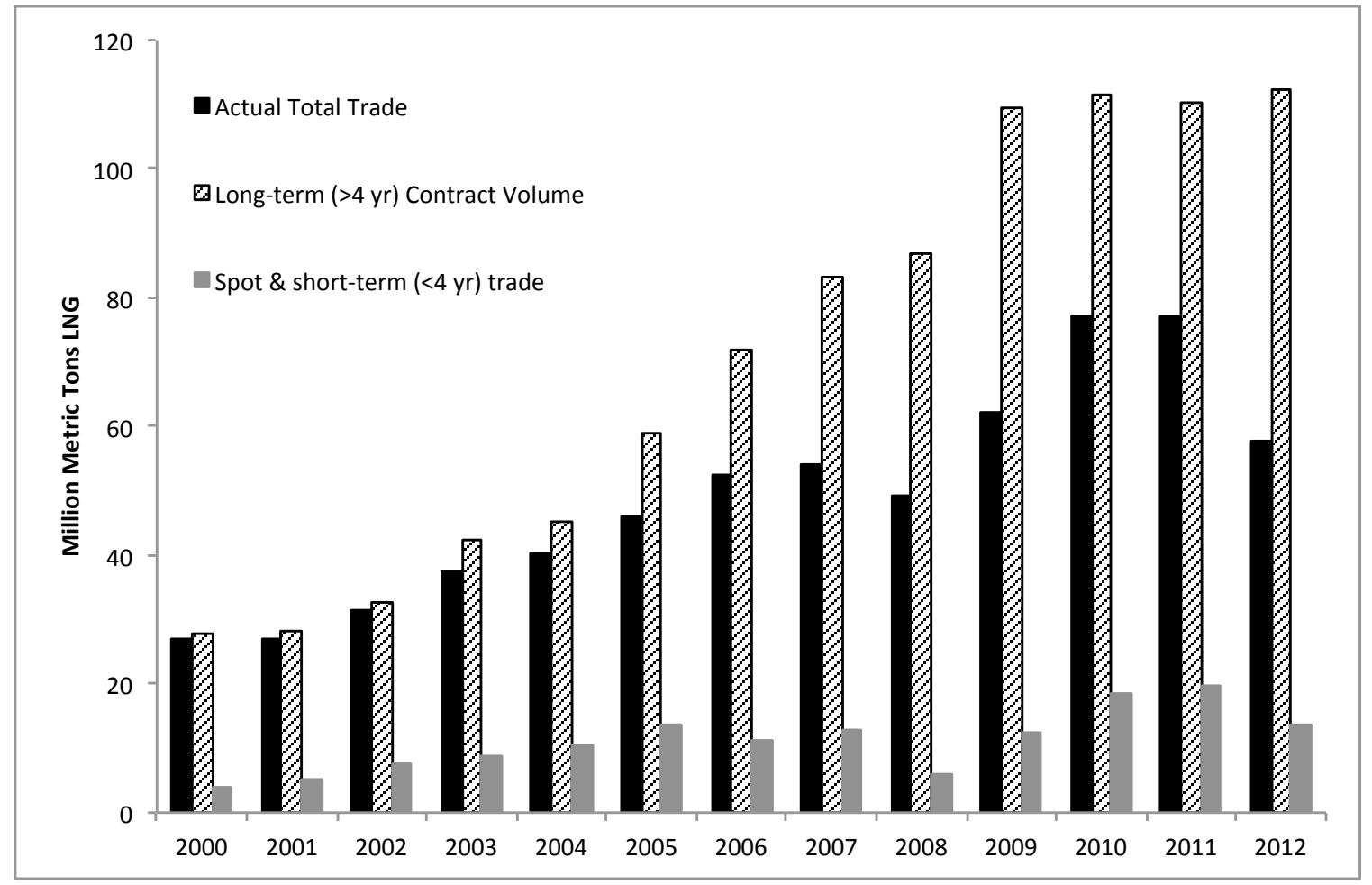

Source: Based on data from the International Group of Liquefied Natural Gas Importers

Pacific Basin

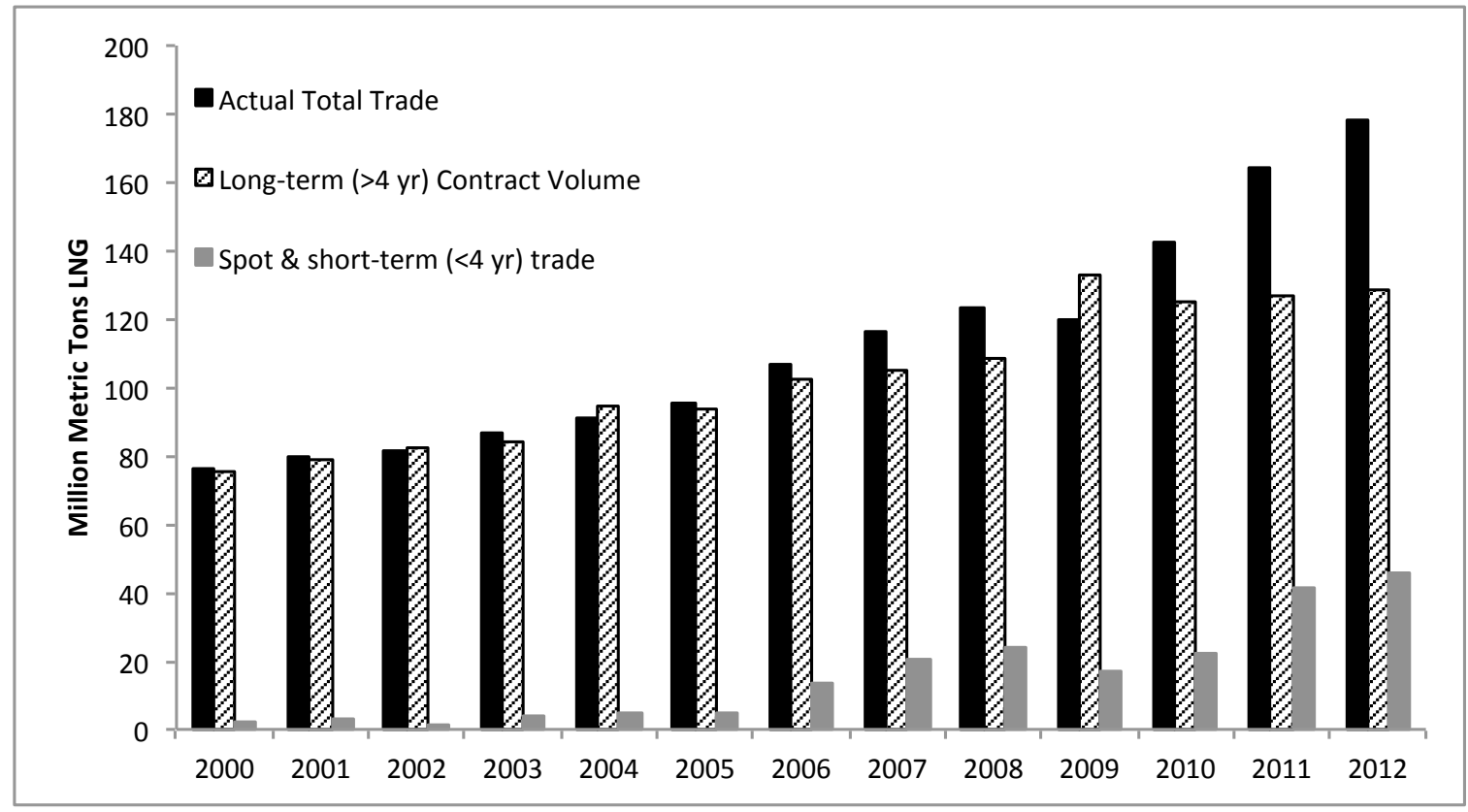

Source: Based on data from the International Group of Liquefied Natural Gas Importers 
Thompson (2009) also notes that, as the LNG market has matured, some early long-term contracts have expired leaving suppliers with spare capacity and without a need to finance large investments. Many of these suppliers have entered the short-term and spot market rather than sign new long-term contracts. Thompson also observes the largest LNG importer in the world, Kogas, has found it difficult to sign long-term contracts. It has a virtual monopoly on LNG imports into Korea, but there is an expectation that the monopoly may end. Thompson also cites Spanish regulations limiting imports from a single supplier, but allowing exemptions for shortterm substitutions.

Figure 1 also reveals that long-term contracted volume exceeded actual trade every year from 2003 in the Atlantic basin. Conversely, actual trade has exceeded the long-term contracted trade in the Pacific basin in most years. Trade from the Atlantic to the Pacific basin may reflect, in part, the progressive elimination of destination clauses in long-term contracts for LNG supply to the European Union (EU). These clauses forbid buyers from re-selling the product to a different destination, allowing a monopolist to earn more revenue through price discrimination. In a competitive market, price differentials between locations are limited to the cost of arbitraging between those locations.

In another paper in IGU (2009), Bezanis and Ahmad discussed the evolution of destination clauses in long-term LNG contracts. While increases in the number of buyers and sellers of LNG have made destination clauses more difficult to enforce, regulatory changes have also played a role. Following the EU restructuring directive of 1998 aimed at promoting competition in European gas markets, the EU Commission found destination clauses to be anti-competitive in 2001. Suppliers of natural gas to Europe have subsequently gradually eliminated such clauses. In turn, this allowed a greater flow of Atlantic-based spot cargoes into the Far East, where economic growth has outpaced growth in Europe. Also writing in IGU (2009), Nakamura remarked that spot market trades had been stimulated by re-export of cargoes from buyer's LNG storage tanks and increased destination flexibility in long-term contracts.

Figure 2, based on data from the Energy Information Administration (EIA), suggests a second reason for the shift of LNG from the Atlantic to the Pacific basin, especially from 2008. US 
monthly LNG imports jumped from mid-2003 through to the end of 2007. The decline from September 2007 largely reflects increased US and Canadian shale gas production. ${ }^{2}$. Firms that had been preparing to export LNG to the US found themselves in need of an alternative market when US imports did not increase as anticipated.

Figure 2. US LNG imports by month

US LNG imports (mmcf/month)

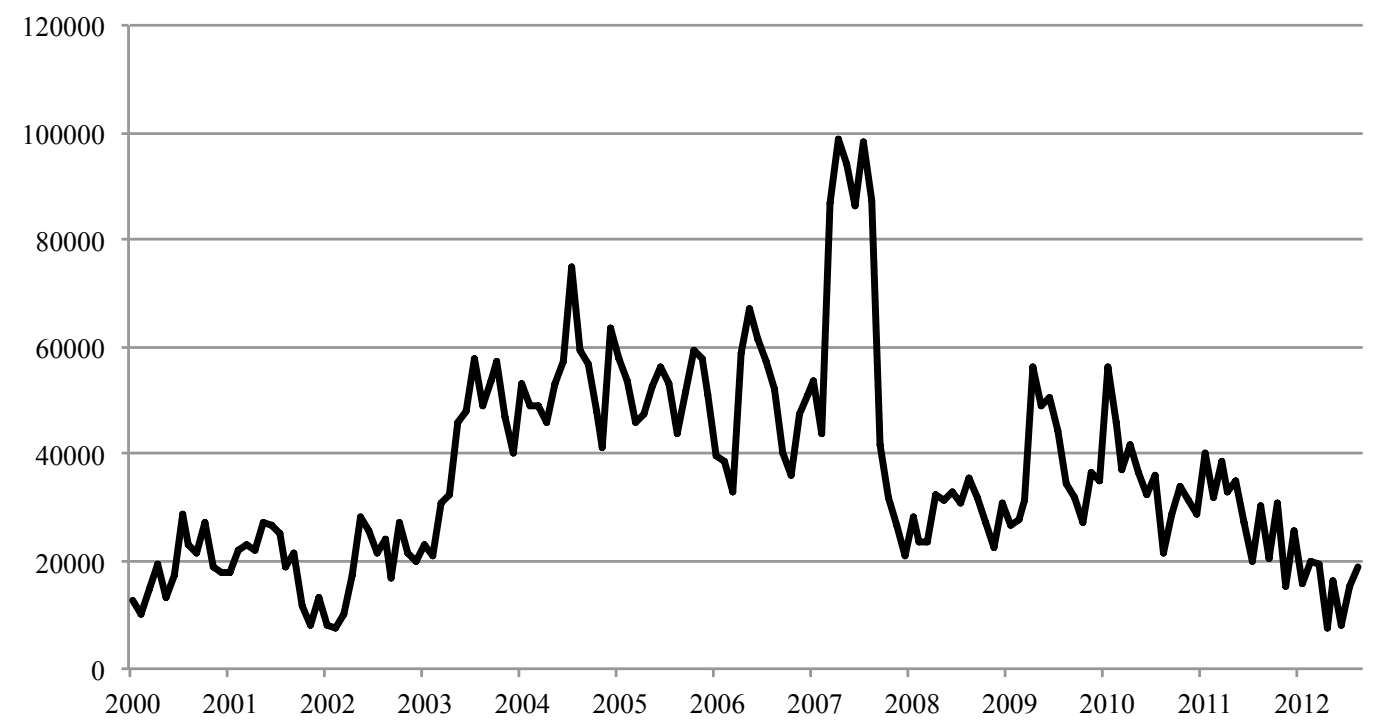

Source: Based on data from the Energy Information Administration

Another reason for the shift in LNG from the Atlantic to the Pacific basin in 2011 (and 2012) was the Fukushima nuclear disaster in Japan in March 2011. Following the disaster, the Japanese government shut down all of Japan's nuclear power plants, greatly increasing the demand for LNG to generate electricity. ${ }^{3}$ Thus Qatar, for example, which had prepared to be a major supplier

\footnotetext{
${ }^{2}$ A referee pointed out that another factor may have been a decline in demand due to the recent economic downturn and some warmer than normal winters. However, while data on natural gas marketed production shows some stagnation or decline in demand from September 2008 through February 2010, demand has grown strongly since then.

${ }^{3}$ According to data from the EIA, following a decline of more than $43.6 \%$ in Japanese nuclear output in 2011 relative to 2010, natural gas consumption (supplied almost entirely by LNG imports) jumped more than $13 \%$ from 2010 to 2011 and more than an additional $0.5 \%$ from 2011 to 2012. The further, almost $89 \%$ decline in nuclear generation in 2012 relative to 2011 was compensated largely by increased coal and oil use, with the consumption of both growing by more than $5.5 \%$ from 2011 to 2012 . While electricity consumption fell by more than $7 \%$ from 2010 to 2011 , it was virtually unchanged from 2011 to 2012 .
} 
to the US market, became instead a major spot and short-term LNG supplier to Japan in 2011 and 2012.

North American prices have become so low relative to European and especially Asian prices that, as of December 2012, ten LNG export facilities have been proposed in the US or Canada, with nine more identified as potential sites. Most of these projects would involve import and export facilities at the same location with pipeline connections to the extremely liquid North American natural gas market. These sites would allow short-term diversions or supplementations of LNG shipments on short notice, and without much affecting prices. Similarly, Thompson (2009) notes that when LNG shipments are destined for liquid markets such as the US or UK, a particular cargo can be diverted elsewhere on short notice, and replacement volumes procured from the liquid destination market. Development of trading hubs in continental Europe will also increase such gas on gas competition and similarly contribute to increased LNG market liquidity.

An export terminal at Elba Island, Georgia proposed by Kinder Morgan and Shell is particularly interesting, since the LNG supply would go to Shell's global portfolio rather than to any particular customer. This project also plans to use modular liquefaction units with lower capacity, but also much lower capital costs per unit of capacity than current technology. Another US LNG export project (at Lake Charles, Louisiana) also is proposing to use a (different) lower capital cost modular technology. The firm behind that project, LNG Ltd, has proposed a similar modular plant at Gladstone in Australia, which will be operated on a tolling arrangement. Similarly, the developers of the proposed Freeport, Texas LNG export plant have signed a liquefaction tolling agreement with BP, who will add the LNG to their worldwide portfolio of supplies.

Hirschhausen and Neumann (2008) and Ruester (2009) present formal statistical analyses of factors affecting long-term natural gas contract duration. Hirschhausen and Neumann examined 311 long-term contracts between natural gas producers and consumers or traders between 1964 and 2006 (122 contracts covering delivery by pipeline and 189 by transport of LNG). They find that contract duration is shorter for deliveries to the US and UK, and to the EU after the 1998 restructuring directive. Contracts related to investments in specific projects are also significantly 
longer than other more general contracts. Conversely, contract extensions or renegotiations, which tend not to be linked to specific new investments, are significantly shorter in duration. Contracts signed by new market entrants were also shorter than those signed by incumbents. Contracts covering a larger volume of trade tended to be significantly longer in term.

Ruester (2009) focused on the LNG market alone. She studied 261 long-term (exceeding three years in duration) LNG contracts including more than $80 \%$ of long-term LNG supply contracts ever written. ${ }^{4}$ The average length for contracts beginning delivery from 2000 was 16.7 years compared to 20.3 years for contracts beginning delivery prior to 2000. Consistent with this, an indicator variable in the regression analysis for contracts beginning delivery from 2000 has a significantly negative effect on duration. Contracts covering a larger share of a regasification terminal's capacity (indicating the asset is more tied to the relationship) are of significantly longer duration. Measuring risk by the standard deviation of the WTI oil price in the year before the contract was signed, she finds weak evidence that greater risk reduces contract duration. ${ }^{5}$ She also finds a statistically significant negative effect on contract duration of three variables measuring repeated interaction between the contracting parties (each variable tested separately). The variables were the cumulative number of times the same parties had negotiated a contract, the cumulative number of years of bilateral trade between them, and an indicator variable for whether the contract was a renewal. She interprets this result as confirming a hypothesis that lower contracting costs and enhanced reputation reduce the risks that a trading partner will behave opportunistically once investments are sunk. However, as Hirschhausen and Neumann (2008) and Thompson (2009) observed, follow-on contracts may involve smaller investments than new trading relationships. The lesser need for financing may allow parties to take on extra risk by retaining more output for spot market trades. Finally, Ruester confirms the finding of Hirschhausen and Neumann that contracts covering deliveries to more competitive markets are of shorter duration.

\footnotetext{
${ }^{4}$ After eliminating some contracts with missing data for some variables, she analyzed 224 contracts.

${ }^{5}$ The variable is not statistically significantly different from zero in some regressions and only significant at the $10 \%$ level in the remaining ones. She interprets the negative sign as reflecting an aversion to "being bound by an agreement that no longer reflects the actual price level." By contrast, the risk we consider later in this paper relates to price variations that leave mean prices unchanged.
} 


\section{Related Theoretical Literature}

This paper builds on an extensive literature, mostly based on the Williamson (1979) transactioncost framework, modeling the benefits of long-term contracts and the effects of contract provisions. Williamson views a long-term contractual relationship as intermediate between spot market transactions and vertical integration of the buyer and seller. As Creti and Villeneuve (2005) emphasize in their survey of literature on long-term natural gas contracts, Williamson's key insight is that durable transaction-specific investments are critical to motivating the demand for long-term contracts. Uncertainty about future demand and supply conditions, and the frequency of recurring transactions, are also important motivations. However, transactionspecific investments expose the parties to ex-post opportunistic behavior and strategic bargaining by their trading partner. Long-term contracts limit the opportunities for such behavior.

As Creti and Villeneuve also emphasize, however, fixing the terms of trade can result in inefficient future trades as supply and demand fluctuate. To mitigate this problem, the contracts allow adjustments that nevertheless are limited in scope to minimize subsequent misinterpretation, dispute and costly adjudication. As Williamson (1979) observes in this regard, while quantity adjustments leave the other party with alternative avenues for making up lost profits, price adjustments are zero-sum.

Take-or-pay clauses are the most common adjustment mechanism in long-term natural gas contracts. ${ }^{6}$ These allow the buyer to unilaterally decide to take less than the contracted volume in return for compensating the seller for the supply that was not taken. Since the decision is unilateral, such options do not require costly verification of exogenous events.

Creti and Villeneuve discuss a paper by Masten and Crocker (1985) that shows that take-or-pay provisions can yield an efficient ex-post outcome. Masten and Crocker assume that the value $v(\theta)$ of the contracted volume to the buyer depends on a random demand shock $\theta$, while the contracted payment to the seller is $y$. Hence, the buyer would not want to take delivery if $v(\theta)<$

\footnotetext{
${ }^{6}$ Weems (2006) notes that these were not present in all LNG contracts signed in the 1960s but became standard in LNG contracts signed in the 1970s. He also observes that take-or-pay provisions remain in recent contracts even though they have allowed more flexibility on other margins.
} 
$y$. Since the value of the trade between the buyer and seller normally exceeds the next best alternative, Masten and Crocker assume that the value $s$ of the next best alternative for the seller is less than the contracted payment $y$. If $v(\theta)<s$, it would be efficient for the buyer to not take the output. But the buyer also would not want to take the output if $s<v(\theta)<y$, even though honoring the contract would be efficient. If the buyer has to pay a penalty $\delta=y-s$ whenever the contracted output is not taken, however, then the contracted output would be refused only when it is efficient to do so.

To implement the efficient take-or-pay rule, the value $s$ of the next best alternative for the seller must be known to both parties. As Masten and Crocker observe, this could be a reasonable assumption regarding the market price for the gas not taken. They further observe, however, that the rule only allows buyers to deviate from the contract. More generally, the efficient allocation will depend on shocks affecting both supply and demand in addition to market prices. Some shocks to supply and demand are likely to be private information that cannot be credibly conveyed to the trading partner, or observed by a third party without incurring a cost.

In the model of a long-term contract examined in this paper, the take-or-pay compensation will be a function of publicly observable prices but will not depend on privately observable demand and supply shocks. While the contract generally will not result in ex-post efficient allocations, we show that the inefficiencies are small.

Canes and Norman (1984) also discuss long-term contracts with take-or-pay clauses. Like Masten and Crocker, they point out that a long-term contract protects investors in large facilities with limited alternative uses against later opportunistic behavior by their trading partners. Canes and Norman also observe that such protection comes at the cost of ex-post inefficient allocations, but take-or-pay provisions can accommodate random demand fluctuations. Although they commented that such provisions thereby "reduce cost of contracting and contribute to the efficient production and utilization of natural gas," they emphasized risk sharing rather than expost allocative efficiency. Specifically, they argued that the risk sharing inherent in a long-term take-or-pay contract provides a more predictable cash flow for both producers and buyers, which 
in turn facilitates financing of their investments with long-term debt. Industry participants often cite similar concerns as the main motivation for long-term contracts. ${ }^{7}$

The benefits from risk sharing will be reflected in our model of a long-term contract. We show that a major advantage of a long-term contract is that it allows both the seller and the buyer of LNG to finance their investments with more debt.

Our paper also contributes to a literature discussing equilibrium market structure when firms can either use long-term contracts or trade in spot markets. In particular, an issue we address is how a change in the spot market environment affects the surplus in a long-term bilateral trading relationship. The paper therefore complements analyses such as Brito and Hartley (2007) that focus on how changes in the surplus generated by different LNG trading arrangements can affect equilibrium market structure.

Specifically, Brito and Hartley (2007) examine a world where matches can generate high or low surplus. Firms need to invest $K$ in infrastructure before a match can generate returns. Firms that have already invested can search in a market for short-term trades, while firms that have yet to invest can search only in a separate, less liquid, long-term bilateral contract market. Brito and Hartley show that there can be four different market structures in a stationary equilibrium:

(i) Firms search for a partner before investing and also search when in a poor match.

(ii) Firms search for a partner before investing but stay in a poor match.

(iii) Firms invest in infrastructure first and continue to search when in a poor match.

(iv) Firms invest in infrastructure first but stay in a poor match.

The second regime resembles the traditional LNG market and is the preferred outcome for the initially chosen parameter values. Brito and Hartley then show that a reduction in $K$, an increase in the number of market entrants each year, and especially an increase in the probability of a

\footnotetext{
${ }^{7}$ In commenting on Canes and Norman (1984) and related papers, Masten and Crocker observed that risk sharing arguments "do not provide a practical basis upon which to evaluate observed contractual arrangements without knowledge of the relative risk preferences of the parties involved." That does not mean, however, that risk-sharing considerations are irrelevant to the demand for long-term contracts.
} 
good match (a parameter in their model), can make the third equilibrium, with maximum spot trading, preferable to the other three.

This paper explains how a small exogenous increase in spot market liquidity could stimulate additional spot market trading and thus increase the probability of finding good matches in the spot market. Simultaneously, the surplus from trading under a long-term contract would decline,

thereby likely reducing the liquidity of the long-term bilateral contract market. Our results thus can be seen as providing additional microeconomic foundations for the model examined by Brito and Hartley.

Nevertheless, the model in this paper need not predict the demise of long-term LNG contracts. A third alternative to traditional long-term contracts or trading only in a spot market is that longterm contracts become more flexible and allow partners to exploit more spot trading opportunities. Brito and Hartley ruled this possibility out by assumption. In their framework, firms trade with only one partner at a time. The long-term contracts we consider allow firms to complement contracted trade with spot market trades. Our results suggest that long-term LNG contracts will continue to evolve toward offering such increased flexibility.

\section{A Model of Long-term LNG Contracts}

In this section, we develop a model of long-term contracting in the LNG industry. The model aims to elucidate why long-term contracts have been so prevalent in the industry. We then use the model to understand how potential future increases in LNG spot market liquidity might affect the nature or viability of long-term contracts. Thus, we assume that the alternative to a long-term contract is trading in a spot market. This contrasts with the models in Crocker and Masten (1988) or Ruester (2009), for example, which assume that absent a long-term contract the trading parties would engage in repeated costly bilateral bargaining.

The main advantage of long-term contracts in our model is that they reduce cash flow volatility, which allows investments to be financed with more debt. On the other hand, contracts may lead 
to some trades that are ex-post inefficient. This happens even though, as emphasized by Masten and Crocker (1985) and others, a take-or-pay clause limits ex-post efficiency losses.

Long-term contracts also have an option value if they allow spot transactions to complement contracted trade. For example, when output is temporarily constrained or spot prices are low, exporters can fulfill their contract obligations by a swap, and when demand is low or spot market prices are high, importers can dispose of surplus contracted volume. The availability of such options reduces the ex-post inefficiency of contracts and helps make them more desirable. The optionality embedded in a contract also introduces substantial non-linearities that make the model impossible to solve analytically. We therefore use a numerical analysis of a stylized environment for trading LNG.

\subsection{The investment projects}

In order to obtain numerical values for the amounts of investments, volumes traded and prices that are representative for the LNG industry, we have used data on projects to cost a 5-mtpy liquefaction plant. The buyers of the LNG will generally also have long-lived investments that they need to finance. In reality, these could include regasification terminals, storage facilities, pipelines, power plants and other industrial facilities. For our purpose, the aggregate cost of these investments is their main feature of interest. To keep the amount of data that we need to gather and explain to a minimum, we assume that no additional regasification, storage or pipeline capacity is needed and that all the natural gas will be used to fuel new CCGT power generation plants.

With approximately 51.322 mmbtu per tonne of LNG, a 5-mtpy plant would produce about $256.6 \times 10^{6} \mathrm{mmbtu} /$ year of natural gas. Using EIA indicative data for CCGT plants, we assume each plant has 400MW capacity and a heat rate of $6.43 \mathrm{mmbtu} / \mathrm{MWh}$. If the plants operate at an average $60 \%$ load factor, each plant would require $13.518 \times 10^{6} \mathrm{mmbtu} /$ year of natural gas. Thus, eighteen CCGT power plants would consume approximately $243.33 \times 10^{6} \mathrm{mmbtu} / \mathrm{year}$ of natural gas. ${ }^{8}$ We aggregate the eighteen power plants into one importer facing the single exporter-owner

\footnotetext{
${ }^{8}$ The $5 \%$ difference from the liquefaction plant output would allow some LNG to be lost in transport.
} 
of the liquefaction plant. We assume both the importer and the exporter maximize after-tax net present value of profits.

Using data on 24 liquefaction plants (culled from news reports) we related real costs (in billions of 2010 US dollars) to the natural log of plant capacity in mtpy. The relationship implies that a 5mtpy plant would cost around $\$ 9.119$ billion. Average real operating cost (excluding cost of feed gas) from the same plants was $\$ 0.28 / \mathrm{mcf}$, which would give tax-deductible variable annual operating costs of around $V_{X}=\$ 0.2726$ million per $10^{6} \mathrm{mmbtu} /$ year.

For the power plants, EIA data suggests a capital cost of $\$ 1.003$ million/MW, implying that eighteen 400MW plants would cost $\$ 7.221$ billion. Fixed operations and maintenance (O\&M) costs of \$0.01462 million/MW implies fixed O\&M of \$105.264 million per year for eighteen 400MW plants. Variable O\&M (excluding fuel) of $\$ 3.11 / \mathrm{MWh}$ and a heat rate of 6.43 $\mathrm{mmbtu} / \mathrm{MWh}$ imply annual non-fuel variable O\&M of $V_{M}=\$ 0.4837 \mathrm{million} / 10^{6} \mathrm{mmbtu}$.

Using data on almost 380 different shipping routes, we found that, beyond about 3,000 miles, marginal shipping costs for LNG per mmbtu were well approximated by a linear function of distance. Assuming a representative distance of about 7,000 miles, we set shipping costs $S=$ $\$ 1.25 / \mathrm{mmbtu}$.

For simplicity, we assume linear demand and supply curves for LNG (this effectively assumes a linear supply curve for feed gas into the plant). Supply and demand are also affected by random shocks, $\xi$ and $\varepsilon$, that cause parallel shifts in the curves. The demand shocks could result, for example, from plant outages, changes in other fuel prices or the prices of other inputs, or shocks to electricity demand. Supply shocks could result, for example, from plant outages, weather shocks, or strikes. In order to have "normal-looking" hump-shaped distributions with finite support, we assume that both shocks follow symmetric beta distributions with a coefficient of 3.25 , but $\varepsilon$ can shift the demand curve intercept by \pm 4 while $\xi$ can shift the supply curve intercept only by \pm 0.7 . We also assume the values of $\varepsilon$ and $\xi$ in any period are not public knowledge, and are too costly to verify to be made the subject of any contract. 
In summary, we assume that the supply of LNG exports is given by

$$
X^{S}=\frac{p_{X}-V_{X}-\delta-\xi}{\gamma}
$$

where $p_{X}$ is the export netback price, $\delta=\$ 1 / \mathrm{mmbtu}^{9}$ is the mean intercept of the supply curve and $\gamma=0.035$ is its slope. Similarly, we assume that demand for LNG is given by

$$
M^{D}=\frac{\alpha+\varepsilon-p_{M}-V_{M}}{\beta}
$$

where $p_{M}$ is the landed price of LNG, $\alpha=\$ 20 / \mathrm{mmbtu}$ is the mean intercept of the demand curve and $\beta=0.035$ is the absolute value of its slope.

The demand and supply price have to differ by $S+V_{X}+V_{M}$. The chosen numerical parameter values therefore imply that, at the mean values of the intercepts, the volume of trade would be $242.768 \times 10^{6} \mathrm{mmbtu} / \mathrm{year}$, and the price to the importer would be $\$ 11.02 / \mathrm{mmbtu}^{10}$ yielding a netback price to the exporter of $\$ 9.77 / \mathrm{mmbtu}$.

The market equilibrium can be represented as in Figure 3. As a result of the envelope theorem, we can interpret the area under the input demand curve between two prices $p_{0}$ and $p_{1}$ as the change in short-run profit resulting from a change in the input fuel price, and the area above the supply curve between two prices $p_{0}$ and $p_{1}$ as the change in short-run profit resulting from a change in output LNG price.

The two parties to this representative long-term contract can also trade in a spot market where prices vary randomly, but do not depend on trades by the two contracting parties. Denote the netback spot price available to the exporter by $p_{X}$ and the delivered spot price available to the importer by $p_{M}$. The destination for a spot cargo from the exporter, and the origin of a spot cargo delivered to the importer, are likely to vary from one transaction to the next. Thus, $p_{X}$ and $p_{M}$ should be positively, but not perfectly, correlated.

\footnotetext{
${ }^{9}$ Note that a price measured as $\$ / \mathrm{mmbtu}$ translates to an equivalent of millions of dollars per $10^{6} \mathrm{mmbtu}$ so the units of $p$ in Figure 3 are millions of dollars.

10 This approximates the National Balance Point (UK) and Japan-Korea Marker prices prior to them separating when the Fukushima disaster occurred.
} 


\section{Figure 3. Trade between the exporter and importer}

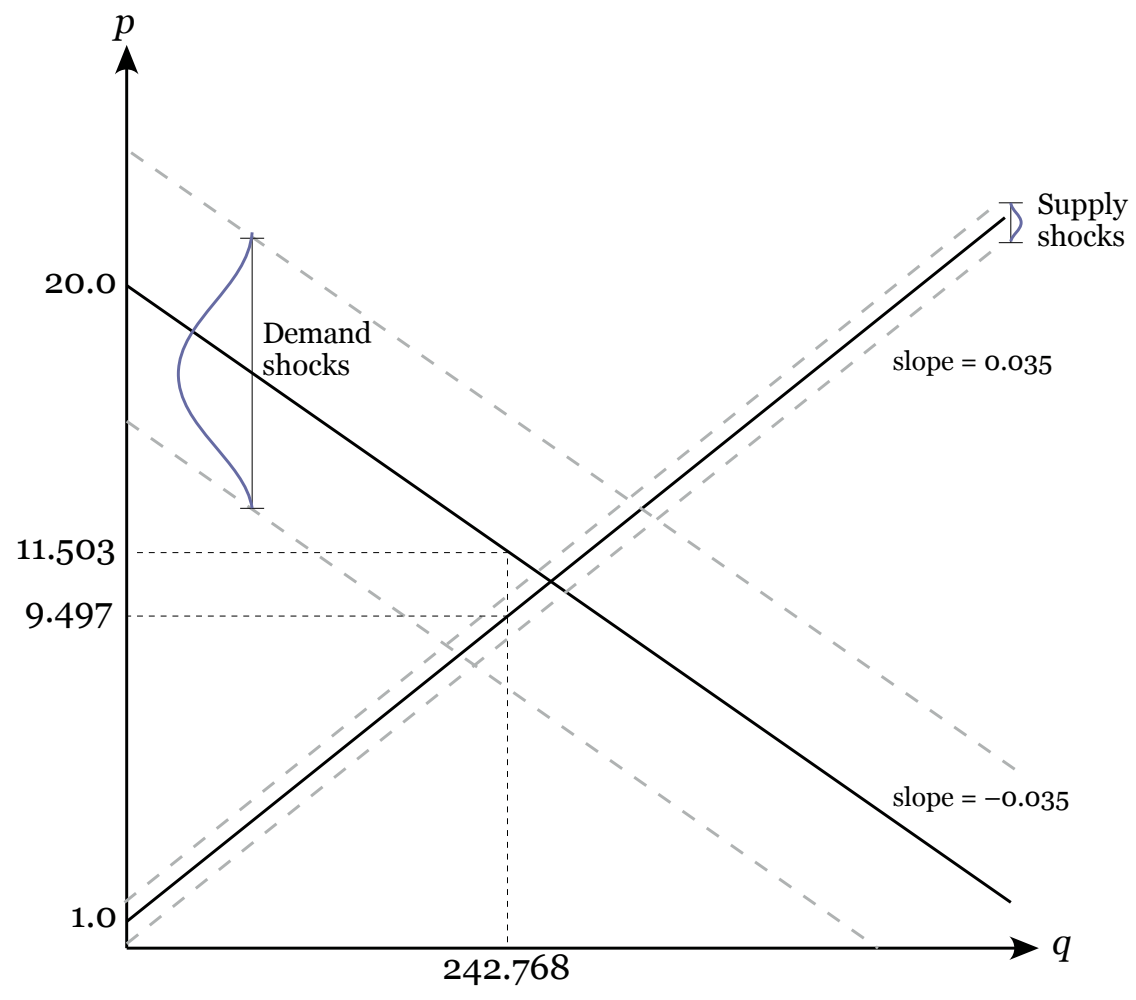

Specifically, we assume that $p_{X}$ can follow various symmetric beta distributions with a mean value of $\$ 8.75$ or $\$ 9.25$ and standard deviations varying from $\$ 0.82$ to $\$ 1.41$. We also assume that $p_{M}$ can be written:

$$
p_{M}=p_{X}+v
$$

where $v$ also follows symmetric beta distributions independent of the distributions of $p_{X}$.

If the spot market is well arbitraged, it would not to be possible to buy LNG at $p_{M}$ pay $S=1.25 / \mathrm{mmbtu}$ to ship it to the exporter location and sell it at a profit for $p_{X}$ so we must have $p_{M}$ $>p_{X}-S$. Thus, the standard deviations and means of $v$ have to be chosen to ensure that the constraint $v>-S=-\$ 1.25$ is never violated. In the examples, the mean of $v$ ranges from $\$ 1.9375$ to $\$ 3.25$, while the standard deviation ranges from $\$ 0.6162$ to $\$ 1.2324$. For these distributions, $\operatorname{Pr}(v>S)=\operatorname{Pr}\left(p_{M}>p_{X}+S\right)$ averages 0.8959 , with a minimum value of 0.7043 and a maximum value of 1.00 . Hence, bilateral trade between the two parties is likely to be preferable to spot trades most of the time. 


\subsection{Financial parameters}

We use the adjusted present value approach to value the two investment projects, assuming that the net benefit of debt can be approximated by its corporate tax benefits alone. The firm's aftertax cash flows, exclusive of tax benefits from depreciation allowances and interest payments, are discounted at the all-equity rate of return of $10 \%$. The corporate tax savings from debt are valued at the debt interest rate of $r_{B}=5 \%$. The tax benefits resulting from the depreciation allowances are valued at the risk-free ${ }^{11}$ rate of interest of $3 \%$. All projects have a 25 -year life with straightline depreciation. The corporate tax rate, $\tau$, is $35 \%$.

In addition, the firms face a "value at risk" type of constraint on the amount of debt they can hold. ${ }^{12}$ Denote the after-tax, but before interest, annual cash flow for particular values of demand $(\varepsilon)$ and supply $(\xi)$ shocks, and export netback $\left(p_{X}\right)$ and delivered import $\left(p_{M}\right)$ spot prices by $C(\varepsilon$, $\left.\xi, p_{X}, p_{M}\right)$. With debt $B$ the after-tax annual interest cost is $(1-\tau) r_{B} B$. We then require that the probability that $C\left(\varepsilon, \xi, p_{X}, p_{M}\right)$ would be insufficient to cover the after-tax interest cost plus $10 \%$ of the principal be just $5 \%$ :

$$
\operatorname{Pr}\left[C\left(\varepsilon, \xi, p_{X}, p_{M}\right)<0.1 B+(1-\tau) r_{B} B\right]=0.05
$$

\subsection{Trading without a contract but under full information}

We examine two scenarios where the parties trade without a contract. To establish a theoretical optimal level of ex-post trade between the parties, we first consider the unrealistic ${ }^{13}$ case where both parties know $V_{X}, V_{M}, \xi$ and $\varepsilon$.

Define two "reference prices" for the exporter and importer such that supply equals demand and the prices differ by exactly the transport cost plus the sum of non-fuel variable costs, $S+V_{X}+V_{M}$ :

$$
\tilde{p}_{X}=\frac{\gamma\left(\alpha+\varepsilon-S-V_{X}-V_{M}\right)+\beta(\delta+\xi)}{\beta+\gamma}
$$

\footnotetext{
${ }^{11}$ The allowances are known for sure once the investment has been made.

${ }^{12}$ As Weems (2006) notes, contracts began to include provisions aimed at “ensuring seller's revenues were not unnecessarily interrupted" as project-financed liquefaction plants became more prevalent in the 1980s.

${ }^{13}$ If trades and prices depended on such information, parties would have an incentive to misrepresent the truth. It may also be impossible or costly for an outside party to verify the truth.
} 


$$
\tilde{p}_{M}=\frac{\gamma(\alpha+\varepsilon)+\beta\left(\delta+\xi+S+V_{X}+V_{M}\right)}{\beta+\gamma}
$$

There are four possible outcomes depending on the current values of $p_{X}$ and $p_{M}$.

Case $1: p_{X}+S \geq p_{M}$

Both the importer and the exporter prefer to use the spot markets. The resulting contributions to variable profits would be

$$
\begin{aligned}
\Pi_{M}^{v} & =\frac{\left(\alpha+\varepsilon-p_{M}-V_{M}\right)^{2}}{2 \beta} \\
\Pi_{X}^{v} & =\frac{\left(p_{X}-V_{X}-\delta-\xi\right)^{2}}{2 \gamma}
\end{aligned}
$$

Case $2: p_{X}+S<p_{M}$

The exporter prefers bilateral trade at a net price of $p_{M}-S$ to spot trade at $p_{X}$. We then have three sub-cases.

Case 2a: $p_{X}-V_{X} \leq \tilde{p}_{X}$ and $p_{M}+V_{M} \geq \tilde{p}_{M}$

Both the importer and the exporter prefer bilateral trade at prices (5) and (6) to spot trade. The resulting contributions to variable profits would be

$$
\begin{aligned}
\Pi_{M}^{v} & =\frac{\left(\alpha+\varepsilon-\tilde{p}_{M}\right)^{2}}{2 \beta} \\
\Pi_{X}^{v} & =\frac{\left(\tilde{p}_{X}-\delta-\xi\right)^{2}}{2 \gamma}
\end{aligned}
$$

Case 2b: $p_{X}-V_{X} \leq \tilde{p}_{X}$ but $p_{M}+V_{M}<\tilde{p}_{M}$

The importer only would prefer to deal in the spot market. Then since the spot market supply curve is perfectly elastic, $p_{M}$ would set the terms for trade between the parties. The importer would pay $p_{M}$, demand $M^{D}$ as given by (2), and earn short-run profit (7). If the exporter wants to 
produce more than $M^{D}$ at $p_{M}-S$, any excess must be sold spot at $p_{X}$. Maximum production at $p_{M}-$ $S$ is thus

$$
X_{M}^{S}=\min \left(\frac{p_{M}-S-V_{X}-\delta-\xi}{\gamma}, M^{D}\right)
$$

and spot market supply from the exporter, if any, would be

$$
X^{S}=\max \left(\frac{p_{X}-V_{X}-\delta-\xi}{\gamma}-X_{M}^{S}, 0\right)
$$

The contribution to the short-run profit of the exporter in this case would be

$$
\Pi_{X}^{v}=\left(p_{M}-S-V_{X}-\delta-\xi-\frac{\gamma}{2} X_{M}^{S}\right) X_{M}^{S}+\left(p_{X}-V_{X}-\delta-\xi-\gamma X_{M}^{S}\right) \frac{X^{S}}{2}
$$

Case 2c: $p_{X}-V_{X}>\tilde{p}_{X}$

We need not consider $p_{M}+V_{M}<\tilde{p}_{M}$ since (recalling that here $p_{X}+S<p_{M}$ ) this would lead to $\tilde{p}_{M}>p_{M}+V_{M}>p_{X}+S+V_{M}>\tilde{p}_{X}+S+V_{X}+V_{M}$, which contradicts the definition of $\tilde{p}_{X}$ and $\tilde{p}_{M}$. Thus, $p_{M}+V_{M} \geq \tilde{p}_{M}$, and we conclude that the importer would prefer to buy from the exporter. Also, since $p_{X}-V_{X}>\tilde{p}_{X}$, the exporter will only trade for at least $p_{X}$. Hence, regardless of where output is sold, the exporter would obtain $p_{X}$. Exporter supply $X^{S}$ would be given by (1) and the contribution to variable profits by (8). If the importer demands more than $X^{S}$ at price $p_{X}+S$ it will have to be bought spot. Product taken from the exporter would then satisfy

$$
M_{X}^{D}=\min \left(\frac{\alpha+\varepsilon-p_{X}-S-V_{M}}{\beta}, X^{S}\right)
$$

and importer spot market purchases, if any, would be

$$
M^{D}=\max \left(\frac{\alpha+\varepsilon-p_{M}-V_{M}}{\beta}-M_{X}^{D}, 0\right)
$$

The contribution to importer short-run profit in this case would be

$$
\Pi_{M}^{v}=\left(\alpha+\varepsilon-p_{X}-S-V_{M}-\frac{\beta}{2} M_{X}^{D}\right) M_{X}^{D}+\left(\alpha+\varepsilon-\beta M_{X}^{D}\right) \frac{M^{D}}{2}
$$




\subsection{Trading without a contract and with public information only}

We now make the more realistic assumption that trade in the absence of a contract must be based solely on $p_{X}, p_{M}$ and $S$. In the sequel, we will refer to this as the PI solution.

Define two reference prices, analogous to (5) and (6), that "split the difference" between $p_{M}$ and $p_{X}+S$ :

$$
\begin{aligned}
& \hat{p}_{X}=\frac{p_{M}+p_{X}-S}{2} \\
& \hat{p}_{M}=\frac{p_{M}+p_{X}+S}{2}
\end{aligned}
$$

along with the corresponding demand and supply at the prices (17) and (18) given by:

$$
\begin{gathered}
\hat{M}^{D}=\frac{\alpha+\varepsilon-\hat{p}_{M}-V_{M}}{\beta} \\
\hat{X}^{S}=\frac{\hat{p}_{X}-V_{X}-\delta-\xi}{\gamma}
\end{gathered}
$$

As in the full information world, we again have four cases.

Case 1: $p_{X}+S \geq p_{M}$

Both parties would prefer to use the spot markets and (7) and (8) would give the contributions to short-run profits.

Case $2: p_{M}>p_{X}+S$

Again there are three sub-cases, now depending on the relative values of $\hat{M}^{D}$ and $\hat{X}^{S}$.

Case 2a: $\hat{M}^{D}>\hat{X}^{S}$

The importer would need to satisfy any additional demand using the spot market. Possible spot market purchases would be

$$
M^{D}=\max \left(\frac{\alpha+\varepsilon-p_{M}-V_{M}}{\beta}-\hat{X}^{S}, 0\right)
$$


The contributions to short-run profits would be

$$
\begin{gathered}
\Pi_{M}^{v}=\left(\alpha+\varepsilon-\hat{p}_{M}-V_{M}-\beta \frac{\hat{X}^{S}}{2}\right) \hat{X}^{S}+\left(\alpha+\varepsilon-\beta \hat{X}^{S}-p_{M}-V_{M}\right) \frac{M^{D}}{2} \\
\Pi_{X}^{v}=\frac{\left(\hat{p}_{X}-V_{X}-\delta-\xi\right) \hat{X}^{S}}{2}
\end{gathered}
$$

Case 2b: $\hat{M}^{D}<\hat{X}^{S}$

The exporter would need to dispose of any surplus supply using the spot market. Possible spot market sales would be

$$
X^{S}=\max \left(\frac{p_{X}-V_{X}-\delta-\xi}{\gamma}-\hat{M}^{D}, 0\right)
$$

The contributions to short-run profits would be

$$
\begin{gathered}
\Pi_{M}^{v}=\frac{\left(\alpha+\varepsilon-p_{M}-V_{M}\right) \hat{M}^{D}}{2} \\
\Pi_{X}^{v}=\left(\hat{p}_{X}-V_{X}-\delta-\xi-\gamma \frac{\hat{M}^{D}}{2}\right) \hat{M}^{D}+\left(p_{X}-V_{X}-\delta-\xi-\gamma \hat{M}^{D}\right) \frac{X^{S}}{2}
\end{gathered}
$$

Case 2c: $\hat{M}^{D}=\hat{X}^{S}$

The contributions to short-run profits would be

$$
\begin{aligned}
\Pi_{M}^{v} & =\frac{\left(\alpha+\varepsilon-\hat{p}_{M}-V_{M}\right)^{2}}{2 \beta} \\
\Pi_{X}^{v} & =\frac{\left(\hat{p}_{X}-V_{X}-\delta-\xi\right)^{2}}{2 \gamma}
\end{aligned}
$$

\subsection{Trading under a contract}

Finally, we consider trading under a long-term contract that has the following features. There is a contract price $p$ paid by the importer for LNG delivered by the exporter to the importer's location. The exporter thus receives a netback price of $p-S$. The contract also specifies a volume $q$ that must be delivered unless both parties agree to a lesser amount. A take-or-pay clause 
requires the importer to compensate the exporter for any loss suffered $\left(p-S-p_{X}\right)(q-M) \equiv \varphi(q-M)$ if the importer takes $M<q$ when $p_{X}<p-S$. Either party can supplement contracted trade with spot market transactions.

We assume the contract terms $p$ and $q$ maximize the sum of the expected net present values of the after-tax profits from the two investment projects. However, we also impose incentive compatibility constraints. The expected net present value of profits obtained by each party under the contract must be non-negative and at least as good as the expected net present value of the profits that party could obtain under the PI solution.

We next discuss the spot and contracted trades for different values of $p_{X}$ and $p_{M}$. We now obtain five cases.

\section{Case 1: $p_{M} \geq p_{X}+S$}

Here, we also have $p_{M}+\varphi=p_{M}+p-S-p_{X} \geq p$, so the importer would prefer to take the contracted supply at $p$ than buy spot at $p_{M}$ and pay $\varphi$. The exporter thus will supply $q$ and may make additional spot market sales at price $p_{X}$

$$
X^{S}=\max \left(\frac{p_{X}-V_{X}-\delta-\xi}{\gamma}-q, 0\right)
$$

The contribution of all the transactions to short-run exporter profit would be

$$
\Pi_{X}^{v}=\left(p-S-V_{X}-\delta-\xi-\frac{\gamma q}{2}\right) q+\left(p_{X}-V_{X}-\delta-\xi-\gamma q\right) \frac{X^{S}}{2}
$$

Case 1a: Importer demand at $p$ is strictly less than $q$.

The importer will sell the difference between the contracted amount and demand at $p_{X}$ and avoid incurring transport cost $S$. Such sales will be at a loss if $p_{X}<p-S$, but the loss would still be less than exercising the take-or-pay clause. The opportunity cost of LNG to the importer will therefore be $p_{X}+S$ and the importer will consume

$$
M_{X}^{D}=\frac{\alpha+\varepsilon-p_{X}-S-V_{M}}{\beta}
$$


The contribution to importer short-run profits will be

$$
\Pi_{M}^{v}=\left(\alpha+\varepsilon-p-V_{M}-\beta \frac{M_{X}^{D}}{2}\right) M_{X}^{D}+\left(p_{X}+S-p\right)\left(q-M_{X}^{D}\right)
$$

Case $1 \mathrm{~b}: M_{X}^{D} \geq q$

The importer may make additional spot purchases at price $p_{M}$

$$
M^{D}=\max \left(\frac{\alpha+\varepsilon-p_{M}-V_{M}}{\beta}-q, 0\right)
$$

and the resulting contribution of all transactions to short-run profits would be

$$
\Pi_{M}^{v}=\left(\alpha+\varepsilon-p-V_{M}-\frac{\beta q}{2}\right) q+\left(\alpha+\varepsilon-\beta q-p_{M}-V_{M}\right) \frac{M^{D}}{2}
$$

Case 2: $p_{M}<p_{X}+S$

We now have three sub-cases to consider.

Case 2a: $p_{X}+S>p$ and the importer wishes to purchase less than $q$ at price $p$

The exporter would agree to sell less than $q$ to the importer at price $p$. Furthermore, using a swap to fulfill the contract avoids the transport cost $S$. The exporter thus purchases

$$
X^{D}=\min \left(\frac{\alpha+\varepsilon-p-V_{M}}{\beta}, q\right)
$$

spot at price $p_{M}$ to make the swap. The exporter then independently makes spot sales at price $p_{X}$ of amount

$$
X^{S}=\frac{p_{X}-V_{X}-\delta-\xi}{\gamma}
$$

The contribution to exporter short-run profits in this case would be

$$
\Pi_{x}^{v}=\left(p-p_{M}\right) X^{D}+\frac{\left(p_{X}-V_{X}-\delta-\xi\right)^{2}}{2 \gamma}
$$

Case $2 \mathrm{~b}: p_{X}+S>p$ and the importer wishes to purchase more than $q$ at price $p_{M}$ 
Importer demand is now given by

$$
M^{D}=\max \left(\frac{\alpha+\varepsilon-p_{M}-V_{M}}{\beta}-X^{D}, 0\right)
$$

The contributions to importer short-run profits would be

$$
\Pi_{M}^{v}=\left(\alpha+\varepsilon-p-V_{M}-\beta \frac{X^{D}}{2}\right) X^{D}+\left(\alpha+\varepsilon-\beta X^{D}-p_{M}-V_{M}\right) \frac{M^{D}}{2}
$$

Case 2c: $p_{M}<p_{X}+S \leq p$

The importer exercises the take-or pay-clause and both parties use the spot markets. The contributions to short-run profits in this case will be

$$
\begin{gathered}
\Pi_{M}^{v}=\frac{\left(\alpha+\varepsilon-p_{M}-V_{M}\right)^{2}}{2 \beta}-\left(p-S-p_{X}\right) q \\
\Pi_{X}^{v}=\frac{\left(p_{X}-V_{X}-\delta-\xi\right)^{2}}{2 \gamma}+\left(p-S-p_{X}\right) q
\end{gathered}
$$

\section{Effects of Changes in the Market Environment}

We are interested in the effects of changes in the probability distributions of the spot market prices since these will affect all bilateral trades simultaneously and in the same way. By contrast, other factors affecting the desirability of long-term contracts are likely to be more stable, and more idiosyncratic, than the market environment.

\subsection{Effects of changes in average spot prices}

We solved for $p$ and $q$, and then a number of other variables of interest in the optimal contract and the two non-contract solutions, for 75 different distributions for $p_{X}$ and $v$. Specifically, for each of two possible means $(\$ 8.75 / \mathrm{mmbtu}$ and $\$ 9.25 / \mathrm{mmbtu})$ for $p_{X}$ and three possible means (\$1.9375/mmbtu, $\$ 2.4375 / \mathrm{mmbtu}$ and $\$ 3.25 / \mathrm{mmbtu}$ ) for $v$, we calculated the solutions for a number of different variances of $p_{X}$ and $v$. For the full set of solutions, the contract price averaged $\$ 11.032 / \mathrm{mmbtu}$ with a standard deviation of $\$ 0.247 / \mathrm{mmbtu}$. The contract volume averaged $232 \times 10^{6} \mathrm{mmbtu} / \mathrm{year}$, with a standard deviation of $5.6 \times 10^{6} \mathrm{mmbtu} /$ year and a range 
from $220.2-241.8 \times 10^{6} \mathrm{mmbtu} /$ year. ${ }^{14}$ Table 1 summarizes average values for $p$ and $q$ and other variables of interest.

Table 1 reveals that uniformly increasing spot market prices (increasing $\mathrm{E}\left(p_{X}\right)$ holding $\mathrm{E}(v)$ fixed) by $50 \notin$ raises the contract price by approximately $45 \varnothing$ and the contract volume by about $4.5 \%$. Such a uniform increase in spot market prices makes bilateral trade more desirable and primarily benefit the supplier, whose costs are not tied to the spot price level. Joint profits are maximized by trading a slight reduction in the average relative price $p / \mathrm{E}\left(p_{X}\right)$ for increased volume $q$. However, the fact that the optimal contract price $p$ rises by almost the full amount of the uniform change in spot prices is consistent with the observed almost full indexation of contract prices to shocks likely to have such a uniform effect.

Table 1. Average values of key variables by spot price distribution means ${ }^{\mathrm{a}}$

\begin{tabular}{|lrr|rrr|}
\hline $\mathrm{E}\left(p_{X}\right)$ & \multicolumn{2}{c|}{8.75} & \multicolumn{3}{c|}{9.25} \\
$\mathrm{E}(\mathrm{v})=\mathrm{E}\left(p_{M}\right)-\mathrm{E}\left(p_{X}\right)$ & 2.4375 & 3.25 & 1.9375 & 2.4375 & 3.25 \\
\hline Number of distributions & 12 & 15 & 15 & 18 & 15 \\
Contract price $p(\$ /$ mmbtu) & 10.68 & 10.97 & 10.90 & 11.10 & 11.42 \\
Contract quantity $q\left(10^{6} \mathrm{mmbtu} /\right.$ year $)$ & 223.09 & 229.59 & 230.90 & 234.57 & 239.35 \\
$\mathrm{E}\left(\mathrm{NPV}_{X}\right)$ under contract $(\$ \mathrm{~m})$ & 45.10 & 487.06 & 463.35 & 749.45 & 1260.92 \\
$\mathrm{E}\left(\mathrm{NPV}_{X}\right)$ full information $(\$ \mathrm{~m})$ & -312.28 & 178.57 & 49.19 & 287.61 & 610.37 \\
$\mathrm{E}\left(\mathrm{NPV} V_{X}\right)$ public information $(\$ \mathrm{~m})$ & -434.10 & 105.19 & 39.87 & 338.46 & 865.71 \\
$\mathrm{E}\left(\mathrm{NPV} V_{M}\right)$ under contract $(\$ \mathrm{~m})$ & 1547.12 & 881.00 & 1233.85 & 785.26 & 137.94 \\
$\mathrm{E}\left(\mathrm{NPV} V_{M}\right)$ full information $(\$ \mathrm{~m})$ & 1662.83 & 1121.91 & 1352.58 & 1016.82 & 660.49 \\
$\mathrm{E}\left(\mathrm{NPV} V_{M}\right)$ public information $(\$ \mathrm{~m})$ & 1533.69 & 792.61 & 1205.90 & 731.30 & 55.10 \\
Debt $B_{X}$ under contract $(\$ \mathrm{~m})$ & 5176.72 & 5490.05 & 5430.67 & 5634.68 & 6004.37 \\
Debt $B_{X}$ full information $(\$ \mathrm{~m})$ & 3827.87 & 4435.16 & 4135.53 & 4375.31 & 4748.26 \\
Debt $B_{X}$ public information $(\$ \mathrm{~m})$ & 3612.66 & 4016.04 & 3997.10 & 4157.08 & 4492.09 \\
Debt $B_{M}$ under contract $(\$ \mathrm{~m})$ & 3162.26 & 2785.63 & 2966.36 & 2724.92 & 2308.40 \\
Debt $B_{M}$ full information $(\$ \mathrm{~m})$ & 3277.38 & 3292.48 & 2917.39 & 2875.80 & 2850.60 \\
Debt $B_{M}$ public information $(\$ \mathrm{~m})$ & 2620.52 & 2350.06 & 2500.51 & 2285.66 & 1982.46 \\
Contract premium relative to $P I$ & $30.97 \%$ & $34.26 \%$ & $26.54 \%$ & $30.18 \%$ & $34.04 \%$ \\
Importer spot net purchases & 50.12 & 15.96 & 53.34 & 27.07 & 1.10 \\
Exporter spot net sales & 28.48 & 9.83 & 42.86 & 26.63 & 11.66 \\
\hline
\end{tabular}

${ }^{\mathrm{a}}$ There were no feasible solutions for $p$ and $q$ when $\mathrm{E}\left(p_{X}\right)=8.75$ and $\mathrm{E}(v)=1.9375$ since bilateral trade between the exporter and importer is uncompetitive at such low spot prices. When $\mathrm{E}\left(p_{X}\right)=8.75$ and $\mathrm{E}(v)=2.4375$ there also were no feasible solutions for low values for the variances of $p_{X}$ and $v$.

\footnotetext{
${ }^{14}$ Recall that a $5 \mathrm{mtpy}$ LNG plant would produce about $257 \times 10^{6} \mathrm{mmbtu} / \mathrm{year}$, while eighteen $400 \mathrm{MW}$ CCGT power plants operated at $60 \%$ load factor would consume about $243 \times 10^{6} \mathrm{mmbtu} / \mathrm{year}$. Since importer net spot market purchases average $28.6 \times 10^{6} \mathrm{mmbtu} /$ year, the power plants on average operate at a higher than $60 \%$ load factor. Average exporter net spot market sales of $23.8 \times 10^{6} \mathrm{mmbtu} /$ year imply that the LNG plant would on average produce close to the rated $257 \times 10^{6} \mathrm{mmbtu} /$ year.
} 
An increase of $50 \phi$ in the spread $\mathrm{E}(\mathrm{v})$, which corresponds to a decrease in competition for the exporter, raises the contract price by about $20 \phi$ on average and the contract volume by about $1.8 \%$. These are less than half the corresponding effects of an increase in $\mathrm{E}\left(p_{X}\right)$ holding $\mathrm{E}(v)$ fixed. When spot prices available to the importer alone rise, the opportunity cost for the exporter of trading with the importer is unchanged so the increase in contract price is less.

Strictly positive expected net present values of the investment projects imply that the expected returns on the investments exceed the required rates used to discount the cash flow components. For the exporter, $\mathrm{E}\left(\mathrm{NPV}_{X}\right)$ under the contract solutions range from around $0.5 \%$ to almost $14 \%$ of the up-front investment cost of $\$ 9,119$ million. For the importer, $\mathrm{E}\left(\mathrm{NPV}_{M}\right)$ under the contract solutions range from around $1.9 \%$ to more than $21 \%$ of the up-front investment costs of $\$ 7,221$ million.

A uniform increase in spot prices (an increase in $\mathrm{E}\left(p_{X}\right)$ holding $\mathrm{E}(v)$ fixed), or an increase in the average gap $\mathrm{E}(v)$ (holding $\mathrm{E}\left(p_{X}\right)$ fixed), increases $\mathrm{E}\left(\mathrm{NPV}_{X}\right)$ and reduces $\mathrm{E}\left(\mathrm{NPV}_{M}\right)$ in the contract solutions. Again the magnitude of the effect is smaller for the second than for the first type of change.

While the incentive compatibility constraint required only that the contract solution be at least as good as the $P I$ solution, $\mathrm{E}\left(\mathrm{NPV}_{X}\right)$ and $\mathrm{E}\left(\mathrm{NPV}_{M}\right)$ are in fact strictly larger under the optimal contract solutions. Average combined surplus, $\mathrm{E}\left(\mathrm{NPV}_{X}\right)+\mathrm{E}\left(\mathrm{NPV}_{M}\right)$, ranges from $26.54 \%$ to more than $34.26 \%$ above the corresponding PI solutions.

Average $\mathrm{E}\left(\mathrm{NPV}_{X}\right)$ in the no-contract solutions is negative when $\mathrm{E}\left(p_{X}\right)=8.75$ and $\mathrm{E}(\mathrm{v})=2.4375$ so average spot prices are very low. In these cases, bilateral trade would not occur without a contract. 
Average exporter debt under the contract solution ranges from one-third to more than $43 \%$ higher than debt under the $P I$ solutions. ${ }^{15}$ The corresponding percentage differences for the importer range from 16-20\% higher. As hypothesized, the tendency for the contract to stabilize cash flows allows the investing parties to carry more debt.

Higher debt under the contract solutions would increase expected net present values simply because of the assumed tax benefits of debt. However, these implied differences exceed the actual differences in expected net present values. Thus, the contract solutions impose ex-post trading losses that partially offset the gains from extra debt.

The final two rows show that both importer spot market net purchases and exporter spot market net sales increase substantially as the average gap $E(v)$ decreases. With a smaller gap, the probability that $p_{M}<p$ and the probability that $p_{X}>p-S$ both increase, raising the value of the embedded options to trade on spot markets. An increase in $\mathrm{E}\left(p_{X}\right)$ holding $\mathrm{E}(v)$ fixed (that is, higher spot market prices in general) increases exporter net spot sales and decreases importer net spot purchases. ${ }^{16}$

\subsection{Effects of changes in the variability of spot prices}

Changes in spot price variances have non-linear effects on $p$ and $q$ and some other variables of interest. ${ }^{17}$ Options to exploit spot market trades that are implicitly embedded in the contract are affected non-linearly by changes in spot price variances, as are the values of any efficient ex-post trades precluded by the contract. In addition, increased spot price variability raises cash flow variability, thereby increasing the leverage benefits of the contract.

\footnotetext{
${ }^{15}$ The sum of the debt carried by the exporter and the importer is also always higher under the contract solution than under the full information no-contract solutions. However, the importer typically carries more debt under the full information solutions than under the contract solutions.

${ }^{16}$ While average exporter net spot sales in Table 1 are smaller when $\mathrm{E}\left(p_{X}\right)=9.25$ and $\mathrm{E}(\mathrm{v})=2.4375$ than when $\mathrm{E}\left(p_{X}\right)=8.75$ and $\mathrm{E}(v)=2.4375$, the solutions in the former case include an extra six cases where variances are low. Restricting calculations to cases where variances are the same, the average exporter net spot sales when $\mathrm{E}\left(p_{X}\right)=9.25$ and $\mathrm{E}(\mathrm{v})=2.4375$ are 31.07 .

${ }^{17}$ The non-linearities made it difficult to find the optimal contract solutions. Specifically, search algorithms based on calculating local derivatives of the objective often stopped at different solutions when using different starting values. These solutions were evidently local maxima. By contrast, the pattern search algorithm in MatLab always attained the same solution regardless of the choice of starting values.
} 
We summarized the effects of changes in variances by estimating and plotting a set of regression surfaces. ${ }^{18}$ For each pair of values for $\mathrm{E}\left(p_{X}\right)$ and $\mathrm{E}(v)$, the different solutions for $p$ and $q$ and other outcomes of interest are non-linear functions of the standard deviations $\sigma\left(p_{X}\right)$ and $\sigma(v)$ of the two distributions. Each non-linear function can be approximated by a polynomial expansion, which is then used to interpolate values for the variable of interest for other values of $\sigma\left(p_{X}\right)$ and $\sigma(v)$. In practice, we needed to estimate a cubic polynomial to get a reasonable approximation to the solution values. ${ }^{19}$

Figure 4 graphs the approximate solution for the optimal contract price $p$ as a function of $\sigma\left(p_{X}\right)$ and $\sigma(v)$ and for the different values of $\mathrm{E}\left(p_{X}\right)$ and $\mathrm{E}(v) .{ }^{20}$ The effects of $\sigma\left(p_{X}\right)$ and $\sigma(v)$ on $p$ are, at their largest, similar in magnitude to the effects of $\mathrm{E}(v)$. Changes of 30-60ф in $\sigma\left(p_{X}\right)$ and $\sigma(v)$ alter $p$ by at most $25 \phi$, but in several cases the changes in $p$ are much smaller. Figure 5 graphs the corresponding solutions for optimal contract volume $q$.

\section{Figure 4. Approximate contract prices $(\$ / \mathbf{m m b t u})$}
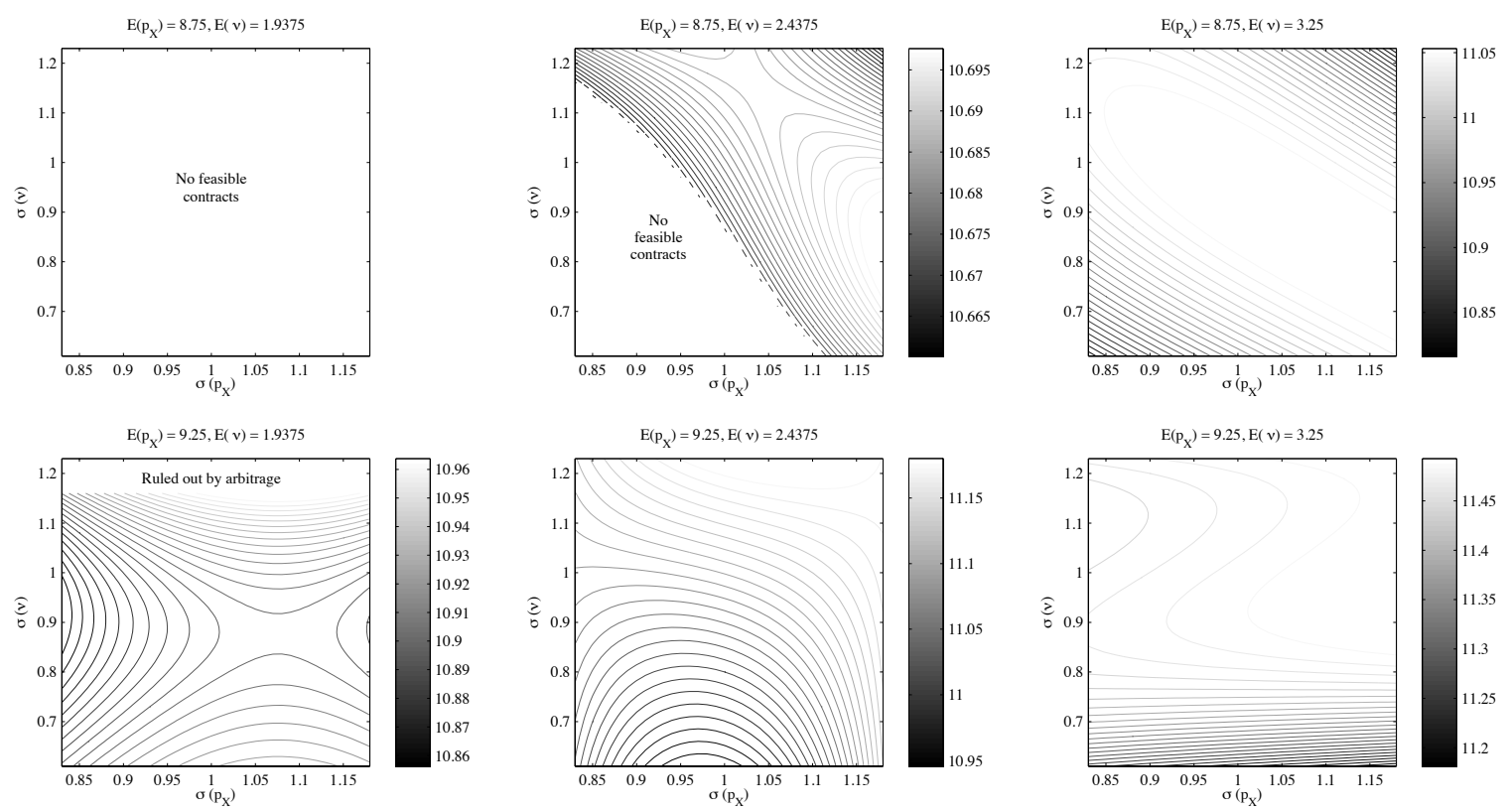

\footnotetext{
18 The solution values underlying the figures plotted in the paper are available from the author on request.

${ }^{19}$ We also fit cubic spline interpolations, which match the solution values exactly. These looked quite similar to the figures in the paper, but were less smooth since the coefficients vary with $\sigma\left(p_{X}\right)$ and $\sigma(v)$.

${ }^{20}$ Since an increase in $p$ redistributes rents from importer to exporter, graphs of the share of rent accruing to the exporter (not included in the paper) look quite similar to the graphs of the optimal contract price $p$.
} 
Figure 5. Approximate contract volumes $\left(10^{6} \mathrm{mmbtu} / \mathrm{year}\right)$
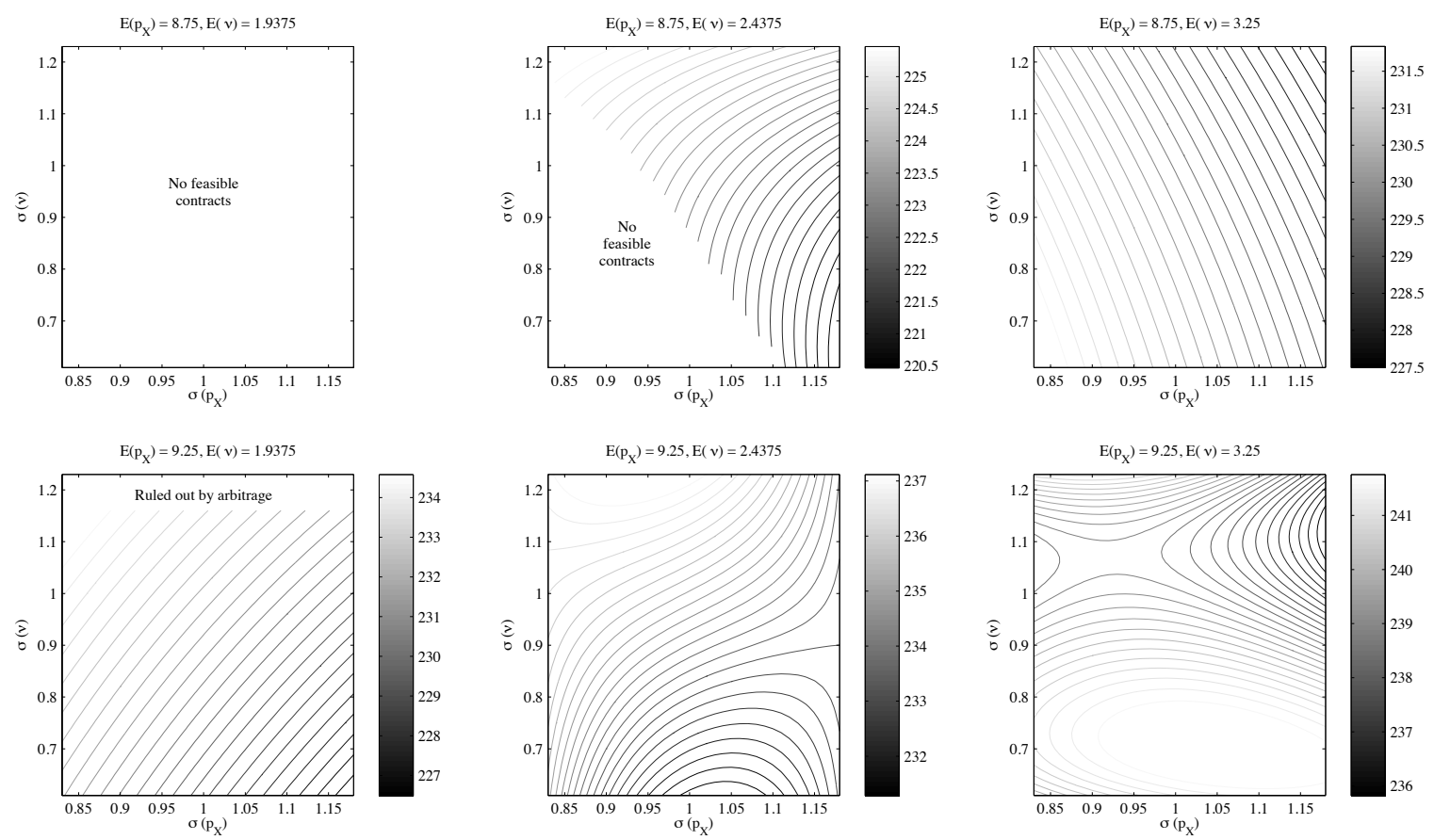

We summarize the effects of changes in $\sigma\left(p_{X}\right)$ and $\sigma(v)$ on $p$ and $q$ as follows. For $\mathrm{E}\left(p_{X}\right)=8.75$ and $\mathrm{E}(v)=2.4375$ or 3.25 , and $\mathrm{E}\left(p_{X}\right)=9.25$ and $\mathrm{E}(v)=1.9375$, increasing $\sigma\left(p_{X}\right)$ holding $\sigma(v)$ fixed decreases $q$, while it increases $p$ at first but then decreases it. For $\mathrm{E}\left(p_{X}\right)=8.75$ and $\mathrm{E}(v)=2.4375$ or 3.25, increasing $\sigma(v)$ holding $\sigma\left(p_{X}\right)$ fixed at first increases $p$ and then decreases it, while the opposite is the case when $\mathrm{E}\left(p_{X}\right)=9.25$ and $\mathrm{E}(v)=1.9375$. Increases in $\sigma(v)$ holding $\sigma\left(p_{X}\right)$ fixed increase $q$ when $\mathrm{E}\left(p_{X}\right)=8.75$ and $\mathrm{E}(v)=2.4375$ or $\mathrm{E}\left(p_{X}\right)=9.25$ and $\mathrm{E}(v)=1.9375$, but decrease it when $\mathrm{E}\left(p_{X}\right)=8.75$ and $\mathrm{E}(v)=3.25$. When $\mathrm{E}\left(p_{X}\right)=9.25$ and $\mathrm{E}(v)=2.4375$, increasing $\sigma(v)$ alone raises both $p$ and $q$, while increasing $\sigma\left(p_{X}\right)$ alone at first decreases and then increases both $p$ and $q$. Finally, when $\mathrm{E}\left(p_{X}\right)=9.25$ and $\mathrm{E}(v)=3.25$, increases in $\sigma(v)$ alone increase $p$ and $q$ at low and high values of $\sigma(v)$, but decrease them both for intermediate values of $\sigma(v)$. Increases in $\sigma\left(p_{X}\right)$ alone increase and then decrease $q$. They also slightly reduce $p$ at low values of $\sigma(v)$, but increase it at higher values of $\sigma(v)$. 
Figure 6. Ex-post trading inefficiencies relative to the full information solution
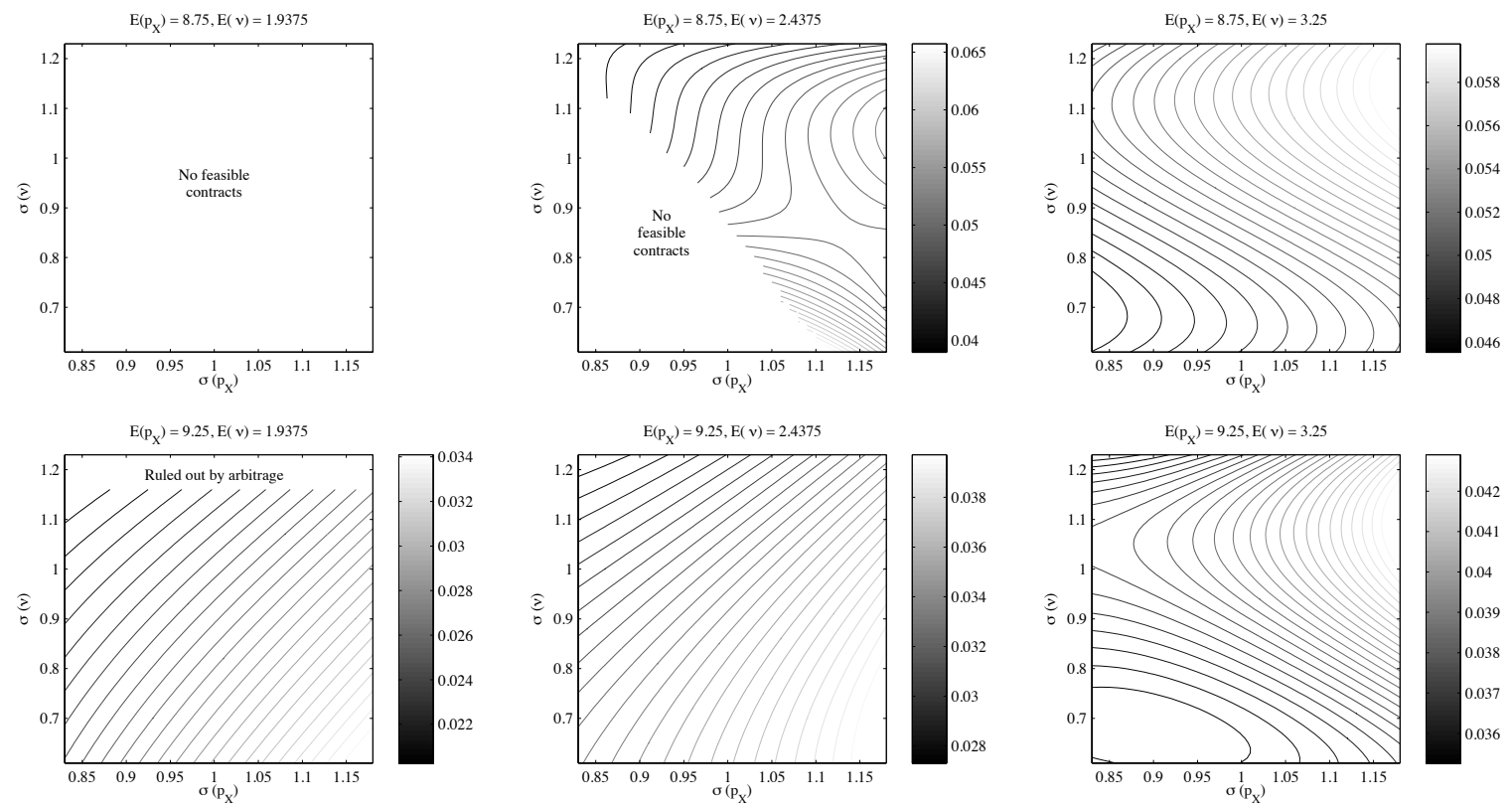

We consider next the ex-post trading losses under the contract. Let $T^{C}$ denote the present value of the tax benefits of the debt issued by both parties under the contract solution, and $T^{F I}$ the present value of the tax benefits of the debt issued under the corresponding full information no-contract solution. Similarly, let $V^{C}$ denote $\mathrm{E}\left(\mathrm{NPV}_{X}\right)+\mathrm{E}\left(\mathrm{NPV}_{M}\right)$ under the contract solution and $V^{F I}$ the corresponding sum under the full information no-contract solution. In every case, $V^{C}-V^{F I}<T^{C}$ $T^{F I}$ but $V^{C}-T^{C}$ (correspondingly $V^{F I}-T^{F I}$ ) represents the contribution of ex-post trades to $V^{C}$ (respectively $V^{F I}$ ). Since the full information no-contract solution guarantees efficient ex-post trades, $V^{F I}-T^{F I}-\left(V^{C}-T^{C}\right)>0$ measures the ex-post trading inefficiencies under the contract solution. ${ }^{21}$ Figure 6 graphs these as a proportion of $V^{F I}$. Their relatively small size (they range from a low of around $2 \%$ to a high of around 6.5\%) helps the contract solution deliver higher rents than the under the $P I$ solution.

From Figures 5 and 6, the trading inefficiencies tend to be relatively low where the contract volumes are relatively high and vice versa. For example, in the second, fourth, and fifth graphs in each figure, low values are in the top left corner in Figure 5 but the bottom right corner in Figure

21 It is important to note that these inefficiencies are not the result of trading as such but are inefficiencies that result from long term contractual limits that preclude some profitable short term trades outside of the contract. 
6. By reducing contract volumes in situations where ex-post trading inefficiencies are likely to be high, the contracting parties can make better use of ex-post profitable spot market trading opportunities.

Figure 7 provides more insight into ex-post profitable spot market trading opportunities under the optimal contracts. To obtain the values approximated in Figure 7, we first summed expected spot market transactions under optimal contracts regardless of whether they are a sale or purchase, and regardless of the whether the transacting party is the exporter or the importer. ${ }^{22}$ We then divided that result by the optimal contract volume.

Figure 7 shows that reduced variability of the gap $\sigma(v)$ decreases spot market transactions, probably because it reduces the value of the embedded options. A reduction in $\sigma\left(p_{X}\right)$ also tends to decrease net spot market transactions, but the effect is much weaker than a reduction in $\sigma(v)$. For $\mathrm{E}\left(p_{X}\right)=9.25$ and $\mathrm{E}(v)=1.9375$, as $\sigma(v)$ approaches the boundary of the region where $\operatorname{Pr}\left(p_{M}+S \leq\right.$ $\left.p_{X}\right)>0$ the total volume of spot market transactions from either party to the contract can exceed $75 \%$ of the contracted volume.

Figure 8 illustrates the effects of the spot price distribution on the additional debt under the contract solution. Because the contracts make cash flows less variable, the contract solutions allow roughly $30 \%$ more debt than the $P I$ solutions. ${ }^{23}$ The additional debt under the contract solutions is not very sensitive to changes in $\mathrm{E}\left(p_{X}\right)$ and $\mathrm{E}(v)$ and, since the contours are close to vertical lines, changes in $\sigma\left(p_{X}\right)$ have a much stronger effect than changes in $\sigma(v)$. The sensitivity of additional debt to $\sigma\left(p_{X}\right)$ is consistent with the hypothesis that the contract allows more debt by stabilizing cash flows.

\footnotetext{
${ }^{22}$ The graphs of spot net sales by the exporter looked very similar to Figure 7, while spot net purchases by the importer looked like the graphs in Figure 7 slightly rotated in the counter-clockwise direction. For $\mathrm{E}\left(p_{X}\right)=9.25$, $\mathrm{E}(v)=3.25$, the importer spot net purchases graph was also translated to the right.

${ }^{23}$ The contract solutions also allow extra debt relative to the full information, but the difference is less.
} 
Figure 7. Gross spot market transactions relative to contracted volumes
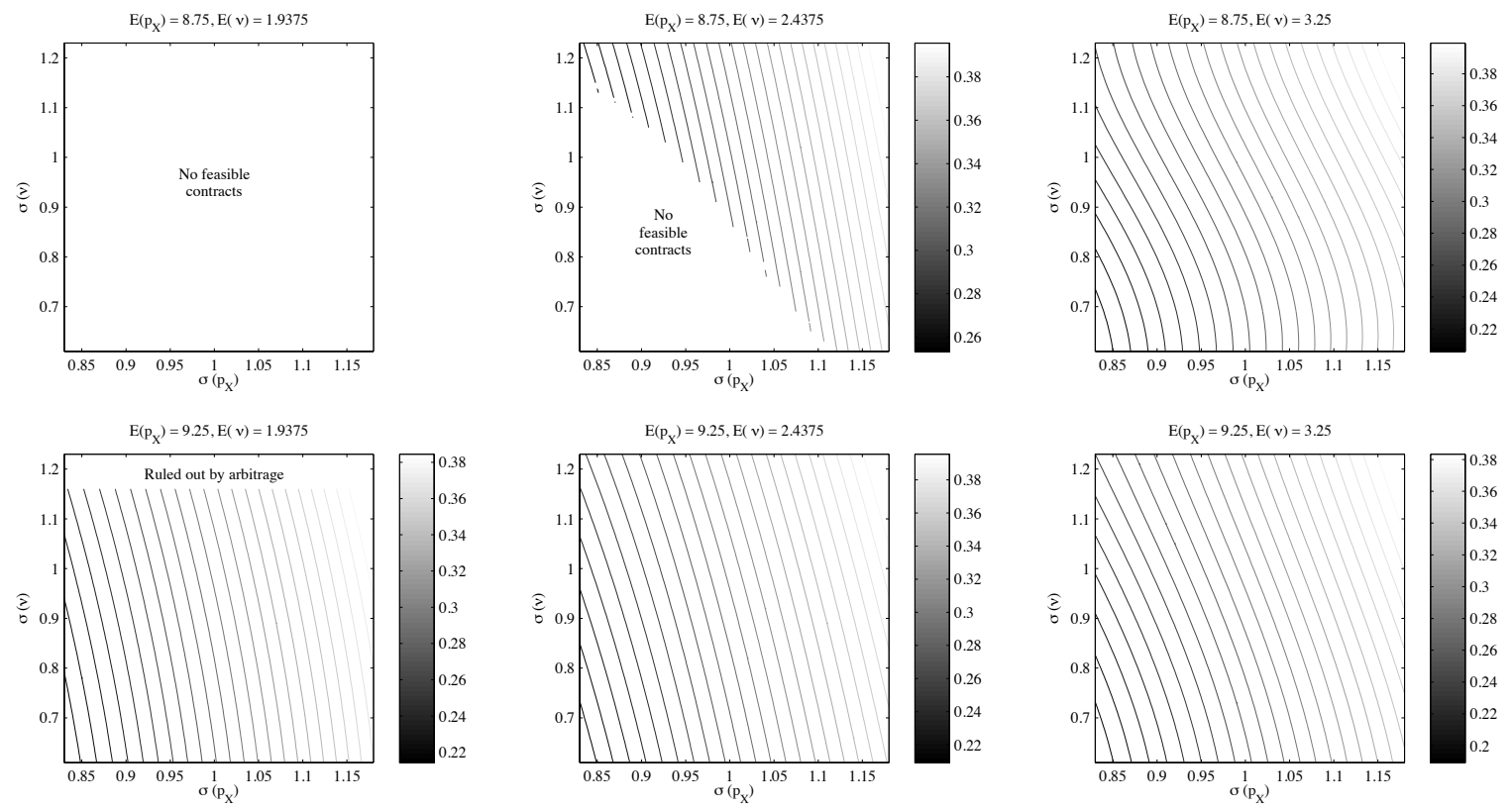

Figure 8. Additional exporter plus importer debt under the contract solutions
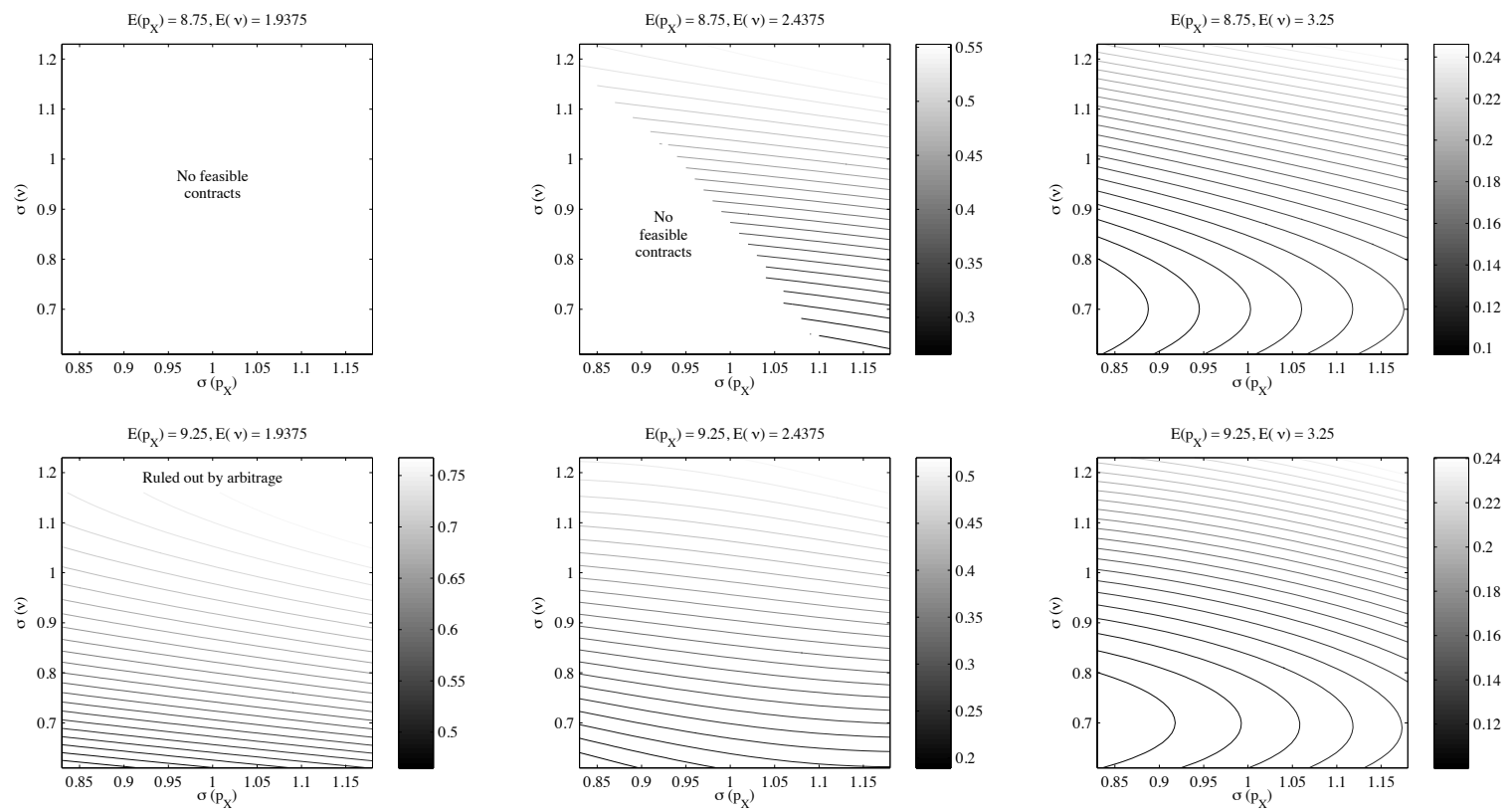

Figure 9 graphs the proportional increase in $\mathrm{E}\left(\mathrm{NPV}_{X}+\mathrm{NPV}_{M}\right)$ under the contract relative to the PI solutions. The graphs in Figures 8 and 9 are quite similar, and much more linear than in 
Figures 4-7. While changes in spot price variances have complicated effects on spot market trading opportunities, non-linear changes in $p$ and $q$ evidently allow cash flows to change much more linearly in response to changes in $\sigma\left(p_{X}\right)$ and $\sigma(v)$. As a result, the additional debt afforded by a contract also changes more linearly. ${ }^{24}$

Figure 9. Contract solution premiums relative to the public information equilibriums
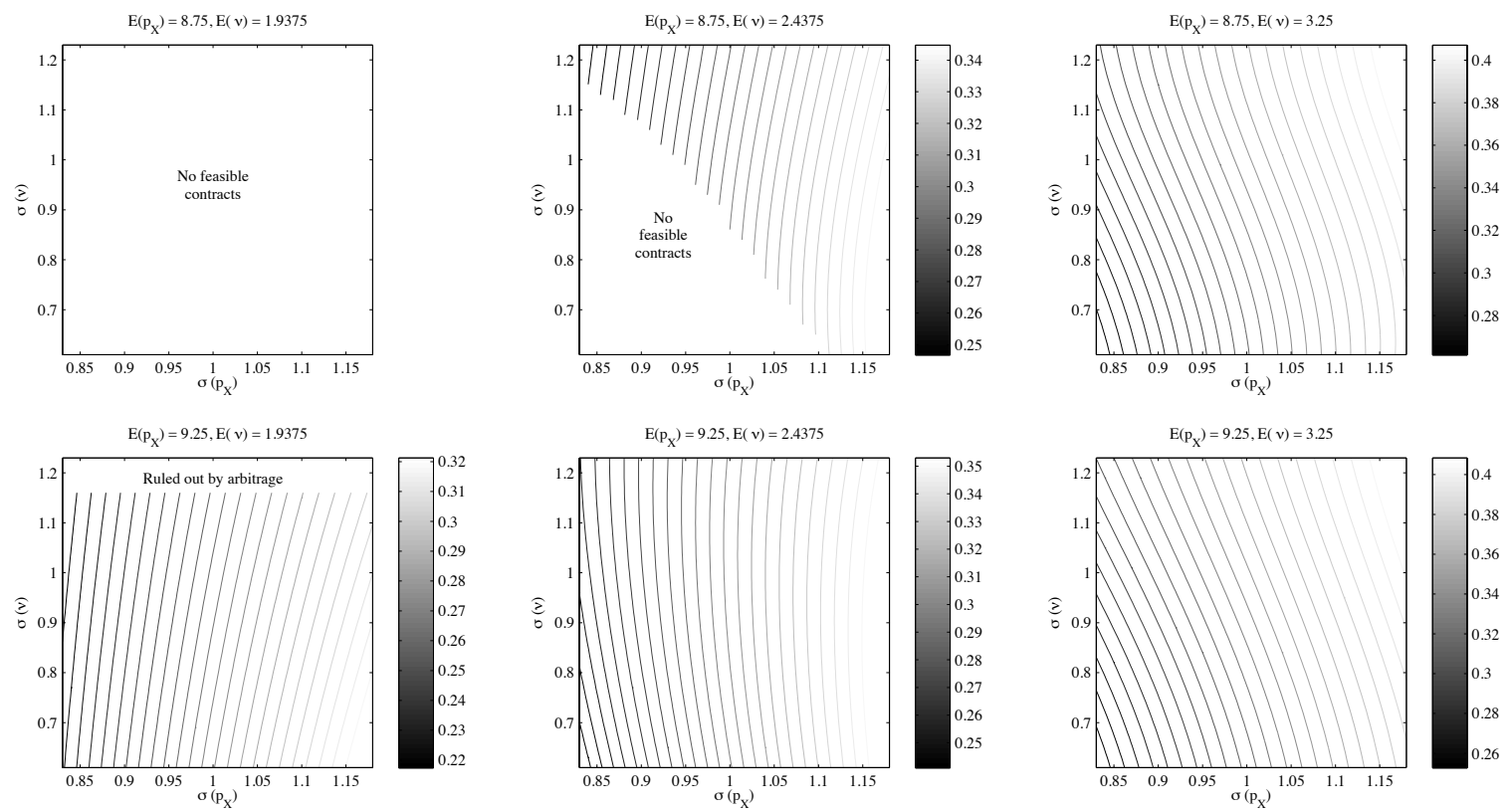

The contract solution yields on average around 30\% higher surplus than the corresponding $P I$ solution. ${ }^{25}$ The advantage of a contract is not much affected by the general level $\mathrm{E}\left(p_{X}\right)$ of spot market prices, but reducing the average gap $\mathrm{E}(v)$ between $p_{M}$ and $p_{X}$ noticeably reduces the benefits of a contract. Figure 9 also reveals that a decrease in $\sigma\left(p_{X}\right)$ substantially reduces the benefits of a contract, but the effect of $\sigma(v)$ is weak and generally more ambiguous. Comparing Figures 8 and 9, the key reason for reduced benefits of a contract as $\sigma\left(p_{X}\right)$ declines is that reduced variability of spot prices also reduces the extra debt under a contract.

\footnotetext{
24 The cubic approximations in Figures 8 and 9 also fit the calculated values much more accurately.

${ }^{25}$ The numerical results also reveal that $\mathrm{E}\left(\mathrm{NPV}_{X}+\mathrm{NPV}_{M}\right)$ under the contract solutions is approximately $12 \%$ higher than the corresponding sum under the spot market solutions based on all full information.
} 


\subsection{Summary of the key results}

Contracts yield a higher joint expected net present value for the participants predominantly because they allow for increased debt finance by making cash flows less volatile. Additional debt under the contract, and the contract premium, both vary substantially with overall spot price variability, but not much with variability in the spread between them.

Although contracts can deliver net benefits overall, they nevertheless also can limit flexibility to exploit profitable trading opportunities. However, inefficiencies arising from contract limitations on spot market trading are not large, with take-or-pay provisions and supplemental spot market trades helping to limit them.

A smaller gap between average spot prices available to the exporter and the importer reduces the advantages of a contract. A smaller gap implies that the pairing is less valuable relative to the alternatives. A smaller gap between average importer and exporter spot market prices also encourages substantially more spot market trading by parties to the contract.

Changes in the variability of spot prices non-linearly affect the values of the options implicitly embedded in long-term contracts, and the values of any efficient ex-post trades precluded by the contract. Such changes therefore have non-linear effects on contract price and volume, ex-post trading inefficiencies, and, to a lesser extent, spot market transactions.

Finally, regarding the issue of indexation of contracts, we found that uniformly increasing spot prices raises the optimal contract price by about $90 \%$ of the price increase. The indexation is not quite $100 \%$ because the costs for the exporter (exclusive of the cost of feed gas) are assumed to be unrelated to the variable raising the natural gas spot prices and some of the benefits of these fixed costs are shared with the buyer. At the same time, the contract volume increases about 4.5\%. Also in response to the increase in spot prices, exporter net spot sales increase and importer net spot purchases decrease. 


\subsection{Effects of increasing spot market liquidity}

As observed in Section 2, the LNG market has recently become considerably more liquid. The numbers of available buyers and sellers have increased, spot and short-term trading has grown, and prices for spot and short-term trades have become less sensitive to individual trades. Increased liquidity should, in turn, reduce the variability of spot prices, denoted $\sigma\left(p_{X}\right)$ in the model.

Entry by new suppliers and demanders also reduces the average distance between any two potential trading partners. This will in turn tend to reduce the gap between average spot prices available to exporters and importers, characterized as E(v) in the model.

From the above analysis, reducing both $\sigma\left(p_{X}\right)$ and $\mathrm{E}(\mathrm{v})$ would reduce the superiority of long-term contracts relative to short-term and spot trading. At the same time, reducing $E(v)$ would greatly increase the amount of spot market trading from parties to existing contracts. Although a simultaneous reduction in $\sigma(v)$ would tend to have the opposite effect, the results in Figure 7 suggest that the change in $\mathrm{E}(v)$ is likely to dominate. Overall, we therefore would expect the advantages of long-term contracts to decline as a result of recent changes in the LNG market.

The evolution of the US natural gas market after 1985, when the Federal Energy Regulatory Commission (FERC) allowed interstate natural gas pipelines to carry gas for their customers as contract carriers, may provide a precedent for how LNG markets could evolve over the next decade or so. As noted by De Vany and Walls (1993), for example, prior to FERC Order 436 the requirement that pipelines buy and sell gas through long-term contracts precluded the development of spot markets for natural gas. De Vany and Walls noted that there were many reasons why deregulation might not have allowed arbitrage to lead to a convergence of natural gas prices: "bottleneck monopolies in the grid; poor coordination between gas purchases and transportation; risk averse buyers reluctant to rely on the spot market, creating a lack of depth and liquidity; excessively volatile prices; distributor city gates that are closed or difficult for buyers to get through; a lack of knowledge and experience on the part of gas producers and buyers long accustomed to regulated prices and long-term contracts; and questions about the incentives of regulated distributors to seek out lower cost gas." Nevertheless, they present 
evidence that by $1987-88,46 \%$ of the pairs of market prices that they examined were cointegrated, ${ }^{26}$ rising to $54 \%$ in $1988-89,65 \%$ in $1989-90$ and $66 \%$ in $1990-91$. They also show that by the end of their sample in 1991 "the degree of cointegration between distant market-pairs approaches the cointegration of near pairs." Furthermore, the pattern of cointegration showed discontinuities that matched the dates various pipelines were opened for access. Although there appeared to be many barriers to market integration, opening access allowed arbitrage and spot trading to develop rapidly.

\section{Concluding comments}

As more firms import LNG, and more producers enter the market, the average difference between spot market prices available to an importer and netback prices available to an exporter will decline. The overall elasticity of supply or demand facing any one party also will tend to increase. The use of natural gas in a wider range of applications may also raise demand elasticities. At the same time, more firms are positioning themselves to take advantage of geographic and intertemporal LNG price differentials. Examples discussed in section 2 include proposed US export terminals collocated with regasification and storage facilities, the flexible portfolio approach to LNG trading by BG and the Singapore and National Grid LNG storage facilities. As a result of these developments, spot market prices are likely to become less variable over time.

The model presented in this paper suggests that these developments will erode the advantages of long-term contracts in allowing higher project leverage. At the same time, the changes are likely to increase spot market participation by parties under contract, further raising spot market liquidity. An increased desire to take advantage of spot and short-term arbitrage opportunities should also raise the demand for greater flexibility in long-term contracts. Accordingly, we can foresee continuing evolution of world LNG markets toward a larger proportion of volumes being traded on short-term contracts or sold as spot cargoes, and increased use of swaps, re-exports and other similar short-term arrangements taking advantage of temporary arbitrage opportunities.

\footnotetext{
${ }^{26}$ As De Vany and Walls observe: "If two price series are within stable arbitrage limits, the 'spread' between them will be stationary and they will be cointegrated. Cointegration, therefore, is the natural test for market integration of stochastically varying prices."
} 


\section{References}

Brito, Dagobert and Peter Hartley. 2007. "Expectations and the Evolving World Gas Market." The Energy Journal, 28(1): 1-24.

Canes, Michael E. and Donald A. Norman. 1984. "Long-Term Contracts and Market Forces in the Natural Gas Market." The Journal of Energy and Development 10(1): 73-96.

Creti, Anna and Bertrand Villeneuve. 2005. "Long-term Contracts and Take-or-Pay Clauses in Natural Gas Markets.” Energy Studies Review 13(1): 75-94.

Crocker, Keith J. and Scott E. Masten. 1988. "Mitigating Contractual Hazards: Unilateral Options and Contract Length.” The RAND Journal of Economics, 19(3): 327-343.

De Vany, Arthur and W. David Walls. 1993. "Pipeline Access and Market Integration in the Natural Gas Industry: Evidence from Cointegration Tests." The Energy Journal, 14(4): $1-19$.

Hirschhausen, Christian von and Anne Neumann. 2008. "Long-Term Contracts and Asset Specificity Revisited: An Empirical Analysis of Producer-Importer Relations in the Natural Gas Industry.” Review of Industrial Organization 32(2): 131-143.

International Gas Union. 2009. “2006-2009 Triennium Work Report, Programme Committee D Study Group 2, LNG, Chapter 3: LNG Contracts," presented to the International Gas Union 24th World Gas Conference, Argentina. Available at http://www.igu.org/html/wgc2009/committee/PGCD/PGCD_Study_Group_2_Report.pdf

Masten, Scott E. and Keith J. Crocker. 1985. "Efficient Adaptation in Long-Term Contracts: Take-or-Pay Provisions for Natural Gas.” American Economic Review 75(5): 1083-1093.

Ruester, Sophia. 2009. “Changing Contract Structures in the International Liquefied Natural Gas Market-A First Empirical Analysis.” Revue D’Économie Industrielle 127(3): 89-112.

Thompson, Stephen. 2009. "The New LNG Trading Model: Short-Term Market Developments and Prospects.” Poten \& Partners, Inc., paper presented to the International Gas Union 24th World Gas Conference, Argentina. Available at http://www.igu.org/html/wgc2009/papers/docs/wgcFinal00351.pdf.

Weems, Philip R. 2006. "Evolution of Long-Term LNG Sales Contracts: Trends and Issues." Oil, Gas and Energy Law, 4(1). 